\title{
3 Research Square \\ Systematic Identification and Analysis of NAC Gene Family in Moso Bamboo (Phyllostachys edulis)
}

\author{
Yameng Gao \\ Anhui Agricultural University \\ Huanlong Liu \\ Anhui Agricultural University \\ Lin Wu \\ Anhui Agricultural University \\ Rui Xiong \\ Anhui Agricultural University \\ Yanan Shi \\ Anhui Agricultural University \\ Yan Xiang ( $\nabla$ xiangyanahau@sina.com ) \\ Anhui Agricultural University
}

\section{Research article}

Keywords: NAC, Microsynteny analysis, Quantitative real-time PCR, Subcellular localization,

Transcriptional activity

Posted Date: March 20th, 2020

DOI: https://doi.org/10.21203/rs.3.rs-18155/v1

License: (c) (i) This work is licensed under a Creative Commons Attribution 4.0 International License.

Read Full License 


\section{Abstract}

Background: NAC (NAM/ATAF1/2/CUC2) gene family is a large plant-specific transcription factor family, which is implicated in many functions, such as morphogenesis, the thickness formation of secondary cell walls as well as biotic and abiotic stress and more. In moso bamboo (Phyllostachys edulis ), 94 PeNACs have been identified and three members are predicted to relate to the secondary cell wall. However, there were few studies on moso bamboo NAC genes under stress.

Results: In this study, we re-identified 165 PheNACs with the latest moso bamboo genome data and divided them into 12 subfamilies using NAM domains. Gene structure and motif distribution manifested the NAC gene family was fairly conserved. Evolutionary analysis showed that the segmental duplication played a significant role in the expansion of NAC genes and the relationship between moso bamboo and Brachypodium distachyon was closest than beween moso bamboo and other four species (Arabidopsis thaliana, Oryza sativa, Sorghum bicolor and Zea mays ). Based on the promoter analysis of the 27 NAC members in A subfamily, quantitative real-time PCR exhibited these genes reacted differently under drought, high salt, abscisic acid and methyl jasmonate treatments. Finally, we selected out four potential stress-associated genes (PheNAC001, -056, -080 and -100) and found they all localized in the tobacco nucleus and had transcriptional activity in yeast.

Conclusions: These preliminary results provide valuable information for mining potential resistance NAC genes and lay theoretical basis for breeding new stress-resistant varieties in moso bamboo.

\section{Background}

Bamboo is a fast-growing plant with many applications for industrial manufacturing, medical materials, ecological landscapes and cultural appreciations in many Asian and African countries [1]. According to the data, approximately 2.5 billion people depend on bamboo economically and the annual international bamboo trade volume exceeds 2.5 billion US dollars. In china, moso bamboo (Phyllostachys edulis) occupies $\sim 73.76 \%$ of the total bamboo-planting area (4.43 million ha), which creates enormous woody products including furniture, paper and musical instruments, and also brings great benefits [1, 2]. In 2013, the first report released $2.05 \mathrm{~Gb}$ of moso bamboo draft genome containing 31987 predicted genes, followed by the publication of the supplementation on chromosome-level reference and alternative splicing atlas in 2018, which was helpful for the classification, evolution and functional analyses of moso bamboo genes $[1,2]$.

Moso bamboo, like other plants, is also forced to encounter multiple adverse environmental stresses throughout the life time, such as drought, cold and high salinity etc. To adapt to these unfavorable conditions, moso bamboo has been and is constantly undergoing evolutionary mechanisms at physiology, biochemical and molecular levels [3]. Generally, when plants are subjected to external stress, they will be induced the production of pivotal enzymes and metabolic proteins, such as dehydrins and late embryogenesis abundant (LEA) proteins [4]. Meanwhile, the receptors on the cell membrane sense 
the stress stimulation and convert it into the signal for intracellular transmission to mediate the expression levels of some responsive genes called regulatory proteins [5]. These regulatory genes will further modulate the expression levels of downstream genes by binding to DNA fragments in the promoter region of the target genes, for instance transcription factors (TFs): AP2/ERF [6], bZIP [7, 8], WRKY [9], MYB [10] and NAC [11] have been identified in rice and Arabidopsis.

For plant-specific transcription factor NAC, one NAM domain is generally located at the N-terminus of the gene and has 150 amino acids [12], which can be further divided into 5 sub-domains (A-E): the ACD sub-domains are relatively conservative; the $B$ and $E$ sub-domains are divergent [13]. The domains from ANAC019-(1-168), NAC2/ORE1-(1-165), ATAF1-(1-165) and VND7-(1-163) can be combined with CGT[GA] or CGT core sequences in vitro [14]. Comparatively, the diverse C-terminal transcription regulation region (TRR) can activate or suppress the transcription of multiple target genes, for instance ANAC019 [14, 15]. Although the $\mathrm{C}$-terminal sequence is variable, simple repeat regions rich in acidic amino acids, prolines, serines, and threons are necessary for transcriptional activation [13]. Also, the area might have transmembrane motifs (TMs), which anchor to the plasma membrane and might relate to signal perception and conduction [15].

To date, researchers have paid more and more attention to NAC genes due to their numerous functions. Accumulating functional reports have showed many NAC genes in rice play key roles in biotic and abiotic stress containing SANC1/OsNAC9 [16], SNAC2/OsNAC6 [17], SNAC3/ONAC003 [18], OsNAC5 [19], OsNAC9 [20], OsNAC10 [21], OsNAP/ONAC058 [22] and OsNAC066 [23]. The overexpression of SNAC1, SNAC2 or ONAC066 in transgenic plants could markedly improve the tolerance to dehydration, cold and salt stresses. Nevertheless, transgenic rice plants of overexpressing the root-specific OsNAC5, OsNAC6, OsNAC9, or OsNAC10 display significant enhancement in drought tolerance. In Arabidopsis thaliana, ANAC019/055/072 have been proven to improve plant tolerance to drought stress by binding to the ERD1 promoter [15]. And ANAC019 and ANAC055 may function as transcription activators to regulate JAinduced expression of defense genes by the anac019 anac055 double mutant and transgenic plants overexpressing of ANAC019 or ANAC055 [24]. The salt-induced AtNAC2/ANAC092 can also integrate the environmental stress and endogenous stimuli to modulate plant lateral root development [25]. Similarly, ATAF1 is a negative regulator of defense responses against both PstDC3000 (Pseudomonas syringae pv.tomato DC3000) and Botrytis cinerea [26], and it also directly regulates abscisic acid (ABA) biosynthetic gene NCED3 by binding its promoter in vivo [27]. Until now, increasing evidences have uncovered NAC genes have great functions not only in biotic and abiotic stress, but also in many other aspects such as cell division [28], the formation and maintenance of sepals and stamens (floral organs) [12], the shoot apical meristem developments [29], leaf senescence [30], flowering time control [31], mediating hormone signaling pathways [32] and starch synthesis [33]. Besides these, NAC genes also participate in secondary cell wall (SCW) biosynthesis in plants. For example, VND6/7 (vascular-related NAC domain) causes an inhibition of secondary wall thickening in vessels [34]. AtXND1 (xylem NAC domain 1) negatively regulates terminal secondary wall biosynthesis [35]. Even, overexpression and RNAi transgenic cotton lines have been verified GhFSN1 positively partakes SCW biosynthesis and modification of fibers [36]. 
For Phyllostachys edulis gene PeSNAC1 (PH01001309G0120), ectopic expression in Arabidopsis thaliana suggests it together with ped-miR164b participates in the regulation of organ boundaries and salinity and drought stresses [37]. In recent years, moso bamboo has received considerable attention in various fields, including its chromosome-level reference genomes and alternative splicing atlas [1], rhizome-related alternative splicing and alternative polyadenylation [38], the phylogeny of phyllostachys [39] and more. Although 94 NAC genes has been identified in moso bamboo and predicted three members (PeNAC8, PeNAC36 and PeNAC73) were related to the secondary cell wall [40], we use the newly issued moso bamboo genome data to re-identify NAC family genes, analyze their basic characteristics, the evolutionary patterns and the expression levels under different stress treatments to quickly find key genes association with stress in this study. Therefore, these results are helpful to understand the characteristics of NAC genes and lay the foundation for revealing moso bamboo internal molecular mechanisms under stress.

\section{Materials And Methods}

\section{Data collection and gene identification}

First, the latest data about Phyllostachys edulis including CDS (coding sequence), peptide sequences, genome sequence and scaffold location information were downloaded from the website (http://gigadb.org/dataset/view/tdsourcetag/s_pcqq_aiomsg/id/100498/File_sort/name/File_page/2). Then the NAC protein sequences from other species (Arabidopsis thaliana, Oryza sativa, Brachypodium distachyon, Sorghum bicolor and Zea mays) including 116 AtNACs [41], 143 OsNACs [42], 114 BNACs [43], 180 SbNACs [44], 144 ZmNACs [45] (some protein sequences were not found at https://phytozome.jgi.doe.gov/pz/portal.html) were used for blast (Basic Local Alignment Search Tool) in moso bamboo latest peptide database with E value $\leq 1 \mathrm{e}-10$ [46]. Next, the obtained results were verified to the existence of NAM domain (PF02365) in pfam website (http://pfam.xfam.org/search). Finally, all predicted proteins were further checked for the complete NAM domain using NCBI website (https://www.ncbi.nlm.nih.gov/Structure/cdd/wrpsb.cgi). Gene length and GC counts were calculated by Fasta Stater TBtools [47]. And the basic properties of amino acids including length, molecular weight (MW) and isoelectric point (pl) were determined at https://web.expasy.org/compute_pi/. Subcellular localization and the membrane-bound were respectively predicted by EuLoc (http://euloc.mbc.nctu.edu.tw/) and PROTTER (http://wlab.ethz.ch/protter/start/).

\section{Phylogenetic tree of PheNACs and OsNACs domains}

After determining the specific location of the NAC protein domain using pfam website, the conserved domain sequences of 143 OsNACs and 165 PheNACs were accurately extracted from their complete amino acid sequence by tbtools software [47]. Then an unrooted tree was constructed using MEGA6 program by the neighbor-joining method with 100 bootstrap values, whereas the single phylogenetic tree of PheNACs was set to 1000 bootstrap values [48]. Moreover, multiple alignments were also carried out through DNAMAN software [49]. 


\section{Gene structure and conserved motifs}

In order to more clearly see the specific positions of exons, introns and domains on genes, GSDS (http://gsds.cbi.pku.edu.cn/index.php) [50,51] was employed to visualize the gene structure. Meanwhile, the PheNAC protein sequences were submitted to MEME online (http://meme-suite.org/tools/meme) with following parameters: maximum number of motifs 10; minimum motif width 6 ; maximum motif width 200 [52].

\section{Scaffold location, duplication relationship and selection pressure}

First, an analytical view for 165 PheNACs were mapped in offline Maplnspect. Then, we used Blastp and MCScanX to examine duplication genes [53]. The paralogous pairs were visualized using Amazing Super Circos; and orthologous pairs between moso bamboo and the other five plants were displayed using Dual Synteny Plotter (https://github.com/CJ-Chen/TBtools). Even all the non-synonymous substitution rate (Ka) and the synonymous substitution (Ks) values of homologous pairs were also measured by TBtools [47]. In genetics, the $\mathrm{Ka} / \mathrm{Ks}$ ratio is an indicator of selective pressure. $\mathrm{Ka} / \mathrm{Ks}>1$ means positive selection; $\mathrm{Ka} / \mathrm{Ks}=1 \mathrm{implies}$ neutral evolution and $\mathrm{Ka} / \mathrm{Ks}<1$ represents purifying selection [54] . Using the formal $\mathrm{T}=\mathrm{Ks} / 2 \lambda(\lambda=6.5 \times 10-9)$, divergence time was also calculated [2]

\section{Gene ontology annotation}

165 NAC protein sequences were loaded into Blast2GO program, then blasted, mapped and annotated to obtain $\mathrm{GO}$ terms, which were mainly divided into three categories: biological process, cellular component and molecular function [55].

\section{Cis-acting element analysis}

The upstream 2-kb promoter region of PheNAC genes were captured from moso bamboo genome sequences and upload to the website (http://planttfdb.cbi.pku.edu.cn/) to detect cis-acting regulatory elements [56].

\section{Plant materials, RNA extraction and quantitative Real-time PCR (qRT-PCR)}

Moso bamboo seeds were collected from Guilin of Guang Xi Province in China, which were identified by the Guilin Forestry Bureau. Then moso bamboo seedlings were cultivated for 8 weeks in $25 \pm 2{ }^{\circ} \mathrm{C}$ greenhouse photoperiod for $16 \mathrm{~h}$ light/8 $\mathrm{h}$ dark. And $200 \mathrm{mM} \mathrm{NaCl}$ [43], $100 \mu \mathrm{M}$ methyl jasmonate (MeJA) [54] and $100 \mu \mathrm{M}$ abscisic acid (ABA) [50] were sprayed on the leaves. For drought stress, $20 \%$ PEG6000 [44] were selected to irrigate the roots. The samples for RNA extraction were collected at 0,1 , $3,6,12$ and 24 hours after treatments.

RNA isolation of moso bamboo leaves were manipulated with RNAiso Plus (TaKaRa Code No.9108) according to the manufacturer's protocol. Then the cDNA was synthesized using thePrimeScript ${ }^{\mathrm{TM}}$ II 1 st Strand cDNA Synthesis Kit (TaKaRa Code No. 6210A) as the instructions described. The reverse 
transcription reaction was at $30^{\circ} \mathrm{C}$ for 10 min followed by $42{ }^{\circ} \mathrm{C}$ for $60 \mathrm{~min}$. In addition, Gene primers were designed using Primer Premier 5.0 software, and moso bamboo CDS library was uploaded manually on the NCBI website to check the primer specificity (Additional file 8: Table S6). The intrinsic membrane protein 41 (TIP41) was used as a reference gene $[57,58]$. The qRT-PCR program was set to $95^{\circ} \mathrm{C}$ for $30 \mathrm{~s}$; 40 cycles of $95^{\circ} \mathrm{C}$ for $10 \mathrm{~s}, 55^{\circ} \mathrm{C}$ for $15 \mathrm{~s}$, and $72{ }^{\circ} \mathrm{C}$ for $10 \mathrm{~s}$.

\section{Subcellular Localization and Transcriptional Activity}

The pCAMBIAl1305 vector with GFP protein driven by 35 S was inserted by CDS with stop codon removed, the fusion vectors were transferred into EH105 strains respectively (BIO-RAD, Hercules, CA, USA) for injection into Nicotiana benthamiana to observe the fusion protein location using confocal laser scanning microscop (CarlZeiss LSM710). In addition, the PheNACs were cloned and independently insert into the pGBKT7 vector (Clontech, Palo Alto, CA, United States), which was used to detect whether the genes had transcriptional activity in yeast. The positive control pGBKT7-53 + pGADT7-T, the negative control pGBKT7 and pGBKT7-PheNAC were respectively transferred to Y2HGold strains (The competent cells purchased from Shanghai Weidi biotechnology Co., Ltd.) according to the instructions. The positive strains were cultured on double deficiency medium (SD/-Trp/-Leu) and the other two groups were grown on single deficiency selection medium (SD/-Trp). Afterwards, we move them to triple deficiency medium (SD/-Trp/-His/-Ade/X-a-Gal) at $30^{\circ} \mathrm{Cfor} 3-5$ days.

\section{Results}

\section{Identification and classification subfamily of moso bamboo NAC genes}

To acquire NAC members in moso bamboo, 697 NAC protein sequences including 116 AtNACs, 143 OsNACs, 114 BNACs, 180 SbNACs and 144 ZmNACs were used as guidance for BLASTP in moso bamboo protein database (Additional file 3: Table S1). Correspondingly, the number of collected moso bamboo protein sequences was $261,269,264,273$ and 264 . We then obtained 279 non-repeating genes by merging and filtering, and further eliminated redundancy and fragmentation. Only 165 members containing the complete NAM domain sequences were named PeNAC001-165 based on their chromosome scaffold location for the subsequent sequence alignment and phylogenetic analysis. In the integrated phylogenetic tree constructed with the domains of 165 PheNACs and 143 OsNACs, the identified 165 proteins were roughly divided into 14 groups (SNAC, ANAC34, OMNAC, TIP, NAM/CUC3, ONAC1, NAC22, SND, NEO, ONAC7, ONAC4, ONAC3, NAC1 and ONAC6) according to previous report (Nuruzzaman et al. 2010) (Fig. 1). However, when drawing phylogenetic trees using moso bamboo protein sequences, only 12 subfamilies appeared and we renamed these subfamilies again from $A$ to $L$ because 6 members (PheNAC034, -047, -78, -102, -053 and -062) in ONAC7 group were divided into B subfamily and PheNAC143 belonging to NEO group was reclassified to $C$ subfamily (The remaining subfamily members remained unchanged) (Fig. 2A). Of the 12 subfamilies, there were 5 subfamilies with over 20 genes: subfamily $A, B, D, E$ and $H$. And the least gene subfamily $C$ had only 3 members which contained the largest protein PheNAC008 (907 amino acids). Coincidentally, PheNAC064 had the shortest 
sequence in protein and gene lengths (141aa, 514bp). For gene GC counts, PheNAC160 and PheNAC162 were the largest and smallest genes, accounting for $69 \%$ and $39 \%$, respectively. The protein MWs were from 15.82 (PheNACO64) to $99.32 \mathrm{kDa}$ (PheNACOO8), and the pls ranged from 4.53 (PheNAC111) to 9.89 (PheNAC006). Unexpectedly, except for PheNAC160 in the cytoplasm, the remaining 164 PheNACs were predicted to be located in the nucleus (Additional file 4: Table S2). In addition to PheNACO3O and PheNAC096, there were also 10 PheNACs with a membrane-bound motif at their own C-terminus, 8 of which were from $\mathrm{H}$ subfamily (Fig. S1).

\section{Gene structure and protein motifs for PheNACs}

To better understand the structural characteristics of moso bamboo NAC gene family, exon/intron structure and motif composition were examined. We counted 9 kinds of exon number $(1,2,3,4,5,6,7,9$ and 11). Among these, the NAC genes with three exons were 120 members $(72.73 \%)$ and with four exons had $16(9.7 \%)$. PheNACOO8 had the most exons (11) and PheNAC097 contained an entire exon. And each gene had only one NAM domain basically distributed on the first two exons. In subfamily $\mathrm{H}$ and $\mathrm{J}$, some genes had longer UTR (untranslated region) (Fig. 2B). Additionally, the genes in a common cluster shared the similar gene structure and motif compositions. For example, the members in subfamily $L$ had three exons, even their lengths were so close and the formation and order of motifs seemed to be completely identical. Surprisingly, 134 members (81.2\%) of nine subfamilies shared the motif 1, 6, 4, 3, 5, 2 and 7. And the motif 1 represented the NAM domain, which was why each NAC gene had it. Moreover, the seven members in subfamily E, their motif compositions were quite consistent and they all contained motif 8 and 10. And motif 9 was discovered in three members PheNAC095, -096 and -097, suggesting they might play special functions (Fig. 2C).

\section{Gene distribution and evolutionary pattern analysis of PheNACs}

A total of 165 PheNACs were mapped onto 23 moso bamboo scaffolds and the highest frequency was observed on scaffold $13(14,8.48 \%)$, followed by scaffold 14, 15, 16 (12, 7.27\%), 3 and 21 (10, 6.06\%). And the six scaffolds contained no less than 10 PheNACs, whereas scaffold 1 was unoccupied by any (Fig. 3A). For NAC gene family evolution, different duplication modes, including 2 pairs of proximal duplication genes, 5 pairs of transposition duplication and 6 pairs of tandem duplication genes, were investigated in moso bamboo genome (Fig. 3A). Most remarkable, 142 segmental duplication gene pairs (involving 145 PheNACs) were also detected, with Ks values ranging from 0.062 to 1.179 (Fig. 3B, Additional file 5: Table S3). Based on previous reports, moso bamboo had undergone two whole-genome duplication (WGD) events and the time of two events was very close (peak Ks:0.499 1.556, recent peak Ks: $0.197 \sim 0.382$ ). Therefore, we roughly attributed 63 genes to derive from the first WGD event (Ks values of 53 pairs were in the range of $0.499 \sim 1.556$ ) and the remaining 82 NAC members might result from the recent WGD event [59]. Meanwhile, we noticed 42 NAC genes correspond to 3 paralogs and 32 members had 2 homologous genes in moso bamboo genome (Additional file 5: Table S3), which might prove moso bamboo genome had experienced two WGD events. Additionally, the ka/ks ratios of 150 
paralogous pairs (Phe-Phe) were lower than 1 (5 paralogous pairs have no Ks value), implying a purifying selection for these PheNACs (Fig. 3C).

\section{Microsynteny analysis of NAC genes between moso bamboo and other five grass species}

To further explore the evolutionary relationships of $N A C$ genes between moso bamboo and and other five species (Arabidopsis thaliana, Brachypodium distachyon, Oryza sativa, Sorghum bicolor and Zea mays), collinear pairs were conducted by BLASTP and MCScanX (Multiple Collinearity Scan). The corresponding numbers of collinear gene pairs between moso bamboo and other five grass species were 13, 177, 215, 202 and 240 respectively. And the NAC genes involved were 9 AtNACs, 70 BNACs, 83 OsNACs, 78 SbNACs and $108 \mathrm{ZmNACs}$. As for Ks, Arabidopsis thaliana (Phe-At) only reserved a Ks value; $80 \mathrm{Ks}$ values were concentrated in 0.4-0.5 (Phe-Bd) and the peak values of $118 \mathrm{Ks}$ were in the range of 0.3-0.5 (Phe-Os); for Sorghum bicolor (Phe-Sb) and Zea mays (Phe-Zm), the Ks values were both concentrated in 0.4-0.6 (Fig. 4B). And the average Ks values between moso bamboo and these four species (except Arabidopsis thaliana) ranged from 0.563 (Phe-Bd) to 0.613 (Phe-Zm), suggesting the evolutionary distance of moso bamboo and Brachypodium distachyon was closest, because moso bamboo diverged from Brachypodium distachyon (Phe-Bd), Oryza sativa (Phe-Os), Sorghum bicolor (Phe-Sb) and Zea mays in turn were 46.9, 48.6, 58.5 and 64.6 million years ago (MYA) (Peng et al., 2013). Also, apart from one pair with 1.0745 (PheNAC160/Bradi5g13300.1), all Ka/Ks ratios of homologous gene pairs were less than 1, representing purified evolution (Fig. 4C, Additional file 6: Table S4).

\section{Gene Ontology Annotations}

To clarify the function of the 165 PheNACs, the gene ontology (GO) was performed and gained $624 \mathrm{GO}$ terms which were divided into three main categories: biological process, cellular component and molecular function (Fig. 5). Both 104 items were implicated in bio-synthetic process and cellular nitrogen compound metabolic process, and 52 were commented on transcriptional regulation, DNA-templated. Totally, the three entries occupied $81.5 \%$ in biological process. Meanwhile, we found 11 items were related to positive regulation of response to salt stress (GO: 1901002), 8 involved in positive regulation of response to water deprivation (GO: 1902584), and 4 responded to cold (GO: 0009409). Actually, the 11 salt-stress genes included the drought and cold-stress genes. In addition, it was unexpected that only one gene (PheNAC047) was interpreted to participate in the cell wall organization or bio-genesis, which was not consistent with the previous report (Shan et al., 2019). However, 125 terms in cellular component were classified into 5 kinds, 120 of them were annotated nucleus (GO: 0005634). Two gene were noted with membrane (PheNAC074 and PheNAC125, GO: 0016020) and one was plasma membrane (PheNAC096, GO: 0061617), which signified the three genes might play an important role in membrane composition. Among total 180 notes of molecular function, 170 terms were assigned to involve binding: 150 were associated with DNA binding, regulation of transcription; 15 were related to sequence-specific DNA (GO: 0043565) and 5genes (PheNAC003, -063, -064,-080 and -100) might concern protein binding (GO: 0005515). The details were seen in Additional file 7: Table S5.

\section{Promoter analysis of SNAC subfamily}


To explore the potential functions of $N A C$ genes, the promoter region of 27 members gathered subfamily A was investigated in the first $2000 \mathrm{bp}$ of the translation initiation site (ATG). Promoter elements were mainly divided into three categories: plant growth and development, abiotic and biotic stress and phytohormone responses.

First and foremost, light responsive elements Sp1, Box 4 and G-Box total 268 accounted for $82.46 \%$, of which 10 or more were detected in 13 members (PheNAC052, -127, -90, -003, -63, -032, -045, -080, -100, $-018,-103,-94$ and -130 ). And the promoter elements of endosperm expression (GCN4_motif) and meristem expression (CAT-box) were also observed among 6 genes and 16 members, respectively. For 02site (zein metabolism) and RY-element (seed-specific regulation), their numbers were 15 and 12, separately. In the second category, both ARE and GC-motif were associated with anaerobic induction. The former was identified within 24 PheNACs with a total of 51, while the latter had 24 out of 15 members.

The low-temperature responsiveness elements (LTR) appeared 34 times among 27 PheNACs with 6 for PheNAC016, and TC-rich repeats occupied 7. And MBS, the MYB binding site involved in droughtinducibility was also identified in 15 members (Fig. 6A). The abscisic acid responsiveness element ABRE ranked the first in the third category and PheNACO80 held the maximum number (22), followed by 94 responsive to MeJA cis-acting elements (CGTCA-motif). And other hormone-related elements including salicylic acid element, gibberellin response elements (P-box, TATC-box and GARE-motif) and auxinresponsive elements (AuxRR-core, TGA-box and TGA-element) were also noticed no more than 3. In addition, three kinds of cis-acting elements (ABRE, CGTCA-motif and MBS) were shown the specific location in the promoter area. We could find 70\% ABRE elements were scattered within the first 1000bp, and some were even concentrated in the first 500bp, for instance PheNAC003, $-032,-045,-80$ and -100 (Fig. 6B).

\section{The expression levels of SNAC genes under different treatments}

Based on the analysis of cis-acting elements and the published related articles, 27 NAC genes were selected for qRT-PCR at five time points under the treatments of drought and high salt, ABA and MeJA. After 20\% PEG6000 treatment, the expression of 15 genes were obviously increased (Fig. 7A), of which 8 had peaked over 10 times than the control group (0h), even PheNAC016 was up-regulated over 40-fold at $24 \mathrm{~h}$. Interestingly, almost these up-regulated genes reached their maximum at $12 \mathrm{~h}$. Conversely, those NAC genes that rapidly decreased after stress treatment were also noted, such as PheNAC077, $-094,-80$ and -110. The strangest behavior was PheNAC056, whose expression was first strongly suppressed at $3 \mathrm{~h}$, then induced up-regulated about 7 -fold at $6 \mathrm{~h}$, and finally down-regulated. For salt stress, PheNAC064, $-050,-103,-077,-052,-130,-94$, and -056 manifested as consistently high expression at all observation time points, the highest expression levels of the last 5 members were more than 20 times. However, the genes that were slightly up-regulated at the initial time point of observation, but in the later period, some tended to express normally, including PheNAC003, -063, -045, -035, and some exhibited higher expression, such as PheNAC061, -080 and -001. In addition, PheNAC048, -016, -090, -085, -015, -032 and -100 showed significant downregulation and the latter three members tended to normal expression in the later stages (Fig. 7B). Unexpectedly, the transcription levels of some PheNACs were strongly inhibited by exogenous 
ABA containing PheNAC048, -016, -003,-103, -080,-032, -100 and -110. And some genes (PheNAC094, $-130,-001,-052,-061,-085,-015$ and -127$)$ were significantly induced, especially the highest expression level of PheNAC001 was more 80 times than that of the control group. Moreover, with the extension of the observation time, some up-regulated genes gradually approached the control value, concerning PheNAC090, -106, -135, -050,-064, -035, -063,-045 and PheNAC077(Fig. 8A). In the MeJA treatment, the majority of NAC genes were severely suppressed (Fig. 8B). The high expression of certain genes was not significant, such as PheNAC035, -032, -018, -063, -056, -085, -110, -127 and -064. Yet three members (PheNAC061, -135 and -077) presented obviously high expression level. Meanwhile, the performance of PheNAC100 attracted our attention, which was repressed at 3 hours, then intensely induced up-regulation at $6 \mathrm{~h}$, then severely suppressed, and finally induced up-regulated about 4 times, PheNAC016 and PheNAC015 did the unstable performance as well.

\section{Subcellular Localization and Transactivation Activity of Four NAC Genes}

It is reported that a large proportion of NAC proteins are located in nucleus $[60,61]$, and the EuLoc website predicted the 164 PheNACs were in the nucleus. Based on GO annotations, cis-acting elements and expression patterns analysis, PheNAC001, $-056,-080$ and -100 were picked for next subcellular localization and transcriptional activity analysis. The CDS without stop codon of four PheNACs independently fused with GFP constructs and the GFP control driven by CaMV 35 S promoter were expressed in Nicotiana benthamiana leaves. The result showed the GFP signal was distributed throughout the cell with the 35S::GFP proteins, and PheNAC001, -056, 080 and -100 proteins were clearly localized in the nucleus, as predicted by the website (Fig. 9).

To investigate the transcriptional activity of the four PheNACs, pGBKT7-PheNACs, the positive control plasmids containing pGBKT7-53 and pGADT7-T, and the negative control plasmid pGBKT7 were independently transformed into the $\mathrm{Y} 2 \mathrm{HGold}$ yeast strain. All of these transformants could grow and displayed visible white colonies on the SD/-Trp medium. In the SD/-Ade/-His/-Trp/X-a-Gal medium, the yeast cells with PheNACs and the positive control grew well and turned blue. In contrast, the negative control did not grow on this medium (Fig. 10). Thence, the four NAC fusion constructs could activate the transcription of the His3 and LacZ reporter genes, demonstrating they had self-transcription activity in yeast strains.

\section{Discussion}

\section{Sequence features}

As a plant-specific large transcription factor family, 165 NAC members were identified and divided into 12 subfamilies based on the report [42]. First, we found the NAM domain with average length $128 \mathrm{bp}$ in pfam was shorter as described 150bp in other articles [62]. Hence, we manually aligned the sequences outside the NAM domain and found $\sim 50 \mathrm{bp}$ following by NAM domain was a certain degree of conservatism. For one subfamily, their NAM domain sequences were quite conserved, whereas great differences existed between different subfamilies (Additional file 2: Fig. S2). As transcription factor, the function of NAC 
genes is mainly dependent on the NAM domain which can combine the promoter region specific cisacting element of different downstream genes or interacts with other proteins. Generally, NAC genes mainly bind to the NACRS with core sequences CACG or CATGTG sequence $[16,63]$. As increasing reports, more NAC genes could combine with different DNA fragments. Arabidopsis transcriptional repressor CBNAC could bind to CBNACBS with a GCTT core sequence but not the CACG sequence [31]. SNAC1 could also recognize an $A B A$ responsive element (ABRE) from OsbZIP23 promoter to monitor the expression level of several ABA signaling genes [64]. Thence, we speculated NAC genes could bind different DNA sequences to participate in different pathways due to distinct NAM domains. On the other hand, NAC gene function need to be controlled by upstream genes. MdHY5 interacted with the G-box from MdNAC52 promoter to affect the MdNAC52 transcription and Anthocyanin and proanthocyanidin (PA) synthesis [65]; $A d N A C 6$ and $A d N A C 7$, the targets for miR164, were both significantly up-regulated by exogenous ethylene in various fruit [66]. For the 165 NAC promoter regions, which contains various cisacting elements such as Sp1, GT1-motif, G-Box and Box 4 involved in light responsive elements, abscisic acid responsiveness element (ABRE) and the MeJA-responsiveness regulatory elements (TGACG/CGTCAmotif), MYB binding site involved in drought-inducibility (MBS) and low-temperature responsiveness elements (LTR) and many more, suggesting they might perform different functions at different stages (statistics but not shown).

In addition, the majority of $N A C$ genes in moso bamboo and other species contained two introns, indicating that the family was structurally conservative (Fig. 2) [43]. Strikingly, the members of subfamily F, PheNAC096/097and PheNAC095/096 were two pairs of paralogous genes, but the three members had different numbers of introns: PheNAC095-(1), PheNAC096-(8), PheNAC097-(0), indicating PheNAC095 and PheNAC097 might lose introns during evolution process. The changes in gene structure might cause gene function change. In comparison with PheNAC066, PheNAC054 and PheNAC057 of subfamily G had one less intron. And PheNAC066 lacked motif 6 and contained two GO terms, whereas PheNACO54 and PheNAC057 were short of motif 4 but had $4 \mathrm{GO}$ terms, which might explain that their function had changed (Fig. 2B, C, Additional file 7: Table S5).

\section{Evolutionary relationships}

In moso bamboo genome, the number for 165 NAC genes is a little more than 118 in Brachypodium distachyon, 151 in rice, 145 in sorghum and 152 in maize, which may be because moso bamboo genome $(1.91 \mathrm{~Gb})$ contains more protein-coding genes (51074) than these monocotyledonous plants [1]. Certainly, NAC gene family has also been widely introduced in many dicotyledonous plants such as Arabidopsis thaliana (116) [41], potato (110) [67], soybean (152) [68], Populus trichocarpa (163) [69] and Asian pears (185) [70] etc. This different numbers might be not only correlated with the size of plant genomes but also related to gene duplication. The genomes of Arabidopsis thaliana (125Mb, 25498 protein coding genes) [71], potato (844Mb, 39031) [72], poplar (385Mb, 45555) [73], Asian pears (527Mb, 59552) [74] and soybean (1.025 Gb, 52051) [75] are smaller than that of moso bamboo and the total number of protein-coding genes varies widely. On one hand, potato has experienced two rounds of whole-genome triplication events (WGT) [72]; Arabidopsis thaliana and soybean have undergone three genome 
duplication events, including two doublings and one triple [76]; in Populus, apart from a triploid event, there is a single "salicoid" duplication event (P-duplication) [73]; Asian pears is similar to poplar, with one doubling and one triple [59]. Moso bamboo undergoes only two whole-genome doubling events, finally leading to an unbalanced gene number in different species. On the other hand, Asian pears, like moso bamboo, segmental duplication seemed to make a greater contribution in NAC gene expansion (Fig. 3A and $\mathrm{B}$ ). We also identified 18 OsNAC genes involved in segmental duplication and 36 members associated with tandem duplication [42]. And in Brachypodium distachyon, both tandem duplicated and segment duplicated genes reached 22 BNACs [43]. In potato, 20, 27, 10 and 46 StNACs were discovered to be segmental, tandem, proximal and dispersed duplicated, respectively [67]. Therefore, different patterns of gene duplication contributed differently to $N A C$ family gene amplification in diverse species.

As for Ks values of NAC orthologous pairs between moso bamboo and Brachypodium distachyon, Oryza sativa, Sorghum bicolor and Zea mays (Phe-Bd, Phe-Os and Phe-Sb, Phe-Zm), the distribution situations were very similar to that of the entire genome (Fig. 4B, Supplementary Figure 11 from [2]), suggesting some PheNACs had appeared before separation from the four species. On the basis of previous article, the divergence time of moso bamboo isolated from Brachypodium, rice, sorghum and maize was approximately $46.9,48.6,58.5$ and 64.6 MYA [2]. And the Ks peak of NAC orthologous pairs between moso bamboo and the four species were all clustered at 0.4-0.5, with corresponding average 0.564 (PheBd), 0.573 (Phe-Os), 0.598 (Phe-Sb) and 0.613 (Phe-Zm) (Additional file 6: Table S4), meaning the closer relationships with moso bamboo were in turn Brachypodium distachyon > Oryza sativa > Sorghum bicolor $>$ Zea mays. This is exactly consistent with the conclusions previously reported [2]. Additionally, in terms of $\mathrm{Ka} / \mathrm{Ks}$ ratios, the values of 32 paralogous pairs (Phe-Phe) containing 43 PheNACs (Fig. 3C), 20 pairs (Phe-Bd), 26 pairs (Phe-Os), 26 pairs (Phe-Sb) and 34 orthologous pairs (Phe-Zm) were between 0.5 and 1 (Fig. $4 \mathrm{C}$ ), signifying these genes were moving forward the direction of positive selection to adapt to the environment [77].

\section{NAC genes response to stresses}

The NAC functions have been well studied in rice [41, 42]. Based on the N-J phylogenetic tree constructed using the domains from 165 PheNACs and 143 OsNACs, NAC genes that clustered together are predicted to have similar potential functions (Fig. 1). In SNAC group, there are six OsNACs with known functions: SNAC1 (LOC_Os03g60080.1), SNAC2/OsNAC6 (LOC_Os01g66120.1), OsNAC3 (LOC_Os07g12340.1), OsNAC5 (LOC_Os11g08210.1) and OsNAC10 (LOC_Os12g03040.1), which have been reported to be associated with biotic and abiotic stress, especially for OsNAC6 (LOC_Os01g66120.1). The gene aggregated with PheNACO80 and PheNAC100 and was induced by cold, high salt, drought and ABA [78]. Over-expressing OsNAC6 in rice exhibited increased tolerance to dehydration and high-salt stresses, as well as blast disease [79]. And the transgenic rice enhanced plant drought tolerance by affecting its direct targets NICOTIANAMINE SYNTHASE to promote the accumulation of the metal chelator NA [80]. Therefore, we speculated that PheNACO80 and PheNAC100 might also have similar functions and regarded them as the study focus. However, their performances were always the opposite under drought and salt treatments. The transcription level of PheNACO80 was suppressed under drought, but 
PheNAC100 was high expression at the observed time points (Fig. 7A). Under salt treatment, PheNAC080 showed high expression at 12 and 24 h yet PheNAC100 presented low expression (Fig. 7B). Thus, their specific functions still need further experiments to explain. In addition, plant hormone ABA and Jasmonic acid (JA) are key regulators of stress signaling networks [81]. When plants suffer from drought or high salt stress, ABA will be generated to control stomatal closure by the SnRK/PP2C signaling pathway and endogenous jasmonic acid (JA) levels generally increase [81-83]. In this study, after ABA-treated, PheNAC080 and PheNAC100 were both low expression, although the former held the most ABRE elements (22) and the latter had 13 ones in their own promoter region. Meanwhile, we also found PheNAC001 was strongly induced by exogenous ABA and it had 8 ABRE elements (Fig 6 \& 8A). The most noticeable is the varied performance of PheNAC100, whose expression was down-regulated first, then suddenly induced up-regulated nearly 20 times, then down and up again. PheNAC056 has the most CGTCA-motif elements (9), whereas its expression level was slightly increased but not significant under MeJA. And OsNAC10 were annotated as the homologous gene of PheNAC001 and PheNACO56, whose overexpression improves rice drought tolerance and grain yield (Jeong et al., 2010). And a grapevine gene VaNAC17 was strongly induced exogenous ABA and methyl jasmonate (MeJA), whose over-expression in Arabidopsis plants enhanced drought tolerance by regulating endogenous JA biosynthesis and ROS scavenging [84]. Thus, these genes are also predicted to have similar functions with great possibility. Finally, we also proved that these four genes are located in the nucleus of tobacco cell and have transcriptional activity in yeast, which could explain the general properties as transcription factors.

\section{Conclusion}

In this study, we carefully re-identified the NAC members in moso bamboo using the latest genome data. After comprehensive investigation and analysis of these NAC genes, qRT-PCR assays showed the expression level of four genes (PheNAC001, -056, -080 and - 100) were induced to extent degree under different stresses, and they were all localized in the nucleus and both had transcriptional activity. To clarify the biological functions and related pathways of these four genes, more experiments need to perform. Thus, this study provides a useful reference for the functional research of NAC family genes.

\section{Additional Files}

Additional file 1: Fig S1. The specific location of membrane-bound motif protein.

Additional file 2: Fig S2. The sequence Alignment of 165 PheNACNAM domains from 12 subfamilies (AK).

Additional file 3: Table S1. NAC gene ID name of five species (Arabidopsis thaliana, Brachypodium distachyon, Rice, Sorghum bicolor and maize).

Additional file 4: Table S2. The detailed information of 165 PheNACs.

Additional file 5: Table S3. Ka, Ks and Ka/Ks values and duplication types of paralogous pairs (Phe-Phe). 
Additional file 6: Table S4. Ka, Ks and $\mathrm{Ka} / \mathrm{Ks}$ values of orthologous pairs between moso bamboo and Arabidopsis thaliana, Brachypodium distachyon, rice, Sorghum bicolor and maize.

Additional file 7: Table S5. Details of 165 PheNACs GO ontology.

Additional file 8: Table S6. The specific primers of quantitative real-time PCR for 27 PheNACs.

Additional file 9: Table S7. The detailed information of motif 1-motif 10.

\section{Abbreviations}

NAC: NAM, ATAF1/2 and CUC2; LEA: late embryogenesis abundant; TRR: transcription regulation region; TMs: transmembrane motifs; PstDC3000: Pseudomonas syringae pv.tomato DC3000; SCW: secondary cell wall; VND:vascular-related NAC domain; XND1: xylem NAC domain 1; CDS: coding sequence; MW: molecular weight; pl: isoelectric point; Ka: non-synonymous substitution rate; Ks: synonymous substitution; MeJA: Methyl Jasmonate; ABA: abscisic acid; UTR: untranslated region; MYA: million years ago; GO: gene ontology; LTR: low-temperature responsiveness elements; ABRE: abscisic acid responsiveness element; MBS: MYB binding site involved in drought-inducibility; JA: jasmonic acid.

\section{Declarations}

\section{Ethics approval and consent to participate}

The seeds of moso bamboo were collected from Guilin in Guang Xi Province, China. And the seeds were provided and identified by the Guilin Forestry Bureau. In addition, all the materials of moso bamboo used and analyzed were available for non-commercial purpose. This article did not contain any studies with human participants or animals performed by any of the authors.

\section{Consent for publication}

Not applicable.

\section{Competing interests}

The authors declare that they have no competing interests.

\section{Funding}

This work was supported by the National Natural Science Foundation of China (31670672), the National Science and Technology Support Program (2015BAD04B0302) and the Graduate Innovation Fund from Anhui Agricultural University (2020ysj-55).

\section{Author contributions}


YMG conceived and wrote the manuscript, HLL participated in organizing figures and tables, LW designed and performed experiments, RX collated and analyzed the experimental data, YNS collected plant materials and assisted to complete the writing of this paper. $Y X$ the correspondent author designed the main frame and provided advice on writing methods of this article. All authors read and approved the manuscript.

\section{Acknowledgments}

We thank the members from the Crop Stress Resistance Breeding and Laboratory of Modern Biotechnology for the help in this study.

\section{Availability of data and materials}

The genome sequences of moso bamboo were downloaded from the website (http://gigadb.org/dataset/view/id/100498/File_sort/name?tdsourcetag=s_pcqq_aiomsg) and these moso bamboo NAC gene IDs were listed in Additional file 4: Table 2. And the NAC proteins sequences of Arabidopsis thaliana, Brachypodium distachyon, Oryza sativa, Sorghum bicolor and Zea mays were obtained from Phytozome database (https://phytozome.jgi.doe.gov/pz/portal.html) and these IDs were listed in Additional file 3: Table 1.

\section{References}

1. Zhao HS, Gao ZM, Wang L, Wang JL, Wang SB, Fei BH, Chen CH, Shi CC, Liu XC, Zhang HL et al: Chromosome-level reference genome and alternative splicing atlas of moso bamboo (Phyllostachys edulis). Gigascience 2018, 7(10).

2. Peng Z, Lu Y, Li L, Zhao Q, Feng Q, Gao Z, Lu H, Hu T, Yao N, Liu K et al: The draft genome of the fastgrowing non-timber forest species moso bamboo (Phyllostachys heterocycla). Nature Genetics 2013, 45(4):456-461.

3. Broun P: Transcription factors as tools for metabolic engineering in plants. Current opinion in plant biology 2004, 7(2):202-209.

4. Nakashima K, Takasaki H, Mizoi J, Shinozaki K, Yamaguchi-Shinozaki K: NAC transcription factors in plant abiotic stress responses. Biochimica Et Biophysica Acta-Gene Regulatory Mechanisms 2012, 1819(2):97-103.

5. Baillo EH, Kimotho RN, Zhang Z, Xu P: Transcription Factors Associated with Abiotic and Biotic Stress Tolerance and Their Potential for Crops Improvement. Genes 2019, 10(10).

6. Wu HL, Lv H, Li L, Liu J, Mu SH, Li XP, Gao J: Genome-Wide Analysis of the AP2/ERF Transcription Factors Family and the Expression Patterns of DREB Genes in Moso Bamboo (Phyllostachys edulis). Plos One 2015, 10(5).

7. Zhao Y, Zhou YQ, Jiang HY, Li XY, Gan DF, Peng XJ, Zhu SW, Cheng BJ: Systematic Analysis of Sequences and Expression Patterns of Drought-Responsive Members of the HD-Zip Gene Family in 
Maize. Plos One 2011, 6(12).

8. Pan F, Wu M, Hu W, Liu R, Yan H, Xiang Y: Genome-Wide Identification and Expression Analyses of the bZIP Transcription Factor Genes in moso bamboo (Phyllostachys edulis). International Journal of Molecular Sciences 2019, 20(9).

9. Cai R, Dai W, Zhang C, Wang Y, Wu M, Zhao Y, Ma Q, Xiang Y, Cheng B: The maize WRKY transcription factor ZmWRKY17 negatively regulates salt stress tolerance in transgenic Arabidopsis plants. Planta 2017, 246(6):1215-1231.

10. Yang KB, Li Y, Wang SN, Xu XR, Sun HY, Zhao HS, Li XP, Gao ZM: Genome-wide identification and expression analysis of the MYB transcription factor in moso bamboo (Phyllostachys edulis). Peerj $2019,6$.

11. Liu MY, Ma ZT, Sun WJ, Huang L, Wu Q, Tang ZZ, Bu TL, Li CL, Chen H: Genome-wide analysis of the NAC transcription factor family in Tartary buckwheat (Fagopyrum tataricum). Bmc Genomics 2019, 20.

12. Aida $M$, Ishida T, Fukaki H, Fujisawa $H$, Tasaka M: Genes involved in organ separation in Arabidopsis: an analysis of the cup-shaped cotyledon mutant. The Plant cell 1997, 9(6):841-857.

13. Olsen AN, Ernst HA, Lo Leggio L, Skriver K: NAC transcription factors: structurally distinct, functionally diverse. Trends in Plant Science 2005, 10(2):79-87.

14. Jensen MK, Kjaersgaard T, Nielsen MM, Galberg P, Petersen K, O'Shea C, Skriver K: The Arabidopsis thaliana NAC transcription factor family: structure-function relationships and determinants of ANAC019 stress signalling. Biochemical Journal 2010, 426:183-196.

15. Tran LSP, Nakashima K, Sakuma Y, Simpson SD, Fujita Y, Maruyama K, Fujita M, Seki M, Shinozaki K, Yamaguchi-Shinozaki K: Isolation and functional analysis of Arabidopsis stress-inducible NAC transcription factors that bind to a drought-responsive cis-element in the early responsive to dehydration stress 1 promoter. Plant Cell 2004, 16(9):2481-2498.

16. Hu H, Dai M, Yao J, Xiao B, Xiong L: Overexpressing a NAM, ATAF, and CUC (NAC) transcription factor enhances drought resistance and salt tolerance in rice. Proc Natl Acad Sci U SA 2006, 103(35):12987-12992.

17. Hu HH, You J, Fang YJ, Zhu XY, Qi ZY, Xiong LZ: Characterization of transcription factor gene SNAC2 conferring cold and salt tolerance in rice. Plant Molecular Biology 2008, 67(1-2):169-181.

18. Fang YJ, Liao KF, Du H, Xu Y, Song HZ, Li XH, Xiong LZ: A stress-responsive NAC transcription factor SNAC3 confers heat and drought tolerance through modulation of reactive oxygen species in rice. Journal of Experimental Botany 2015, 66(21):6803-6817.

19. Takasaki H, Maruyama K, Kidokoro S, Ito Y, Fujita Y, Shinozaki K, Yamaguchi-Shinozaki K, Nakashima K: The abiotic stress-responsive NAC-type transcription factor OsNAC5 regulates stressinducible genes and stress tolerance in rice. Molecular Genetics and Genomics 2010, 284(3):173183.

20. Redillas M, Jeong JS, Kim YS, Jung H, Bang SW, Choi YD, Ha SH, Reuzeau C, Kim JK: The overexpression of OsNAC9 alters the root architecture of rice plants enhancing drought resistance 
and grain yield under field conditions. Plant Biotechnology Journal 2012, 10(7):792-805.

21. Jeong JS, Kim YS, Baek KH, Jung H, Ha SH, Do Choi Y, Kim M, Reuzeau C, Kim JK: Root-Specific Expression of OsNAC10 Improves Drought Tolerance and Grain Yield in Rice under Field Drought Conditions. Plant Physiology 2010, 153(1):185-197.

22. Chen X, Wang YF, Lv B, Li J, Luo LQ, Lu SC, Zhang X, Ma H, Ming F: The NAC Family Transcription Factor OsNAP Confers Abiotic Stress Response Through the ABA Pathway. Plant and Cell Physiology 2014, 55(3):604-619.

23. Yuan X, Wang H, Cai JT, Bi Y, Li DY, Song FM: Rice NAC transcription factor ONAC066 functions as a positive regulator of drought and oxidative stress response. Bmc Plant Biology 2019, 19.

24. Bu QY, Jiang HL, Li CB, Zhai QZ, Zhang JY, Wu XQ, Sun JQ, Xie Q, Li CY: Role of the Arabidopsis thaliana NAC transcription factors ANAC019 and ANAC055 in regulating jasmonic acid-signaled defense responses. Cell Research 2008, 18(7):756-767.

25. He XJ, Mu RL, Cao WH, Zhang ZG, Zhang JS, Chen SY: AtNAC2, a transcription factor downstream of ethylene and auxin signaling pathways, is involved in salt stress response and lateral root development. Plant Journal 2005, 44(6):903-916.

26. Wang XE, Basnayake B, Zhang HJ, Li GJ, Li W, Virk N, Mengiste T, Song FM: The Arabidopsis ATAF1, a NAC Transcription Factor, Is a Negative Regulator of Defense Responses Against Necrotrophic Fungal and Bacterial Pathogens. Molecular Plant-Microbe Interactions 2009, 22(10):1227-1238.

27. Jensen MK, Lindemose S, de Masi F, Reimer JJ, Nielsen M, Perera V, Workman CT, Turck F, Grant MR, Mundy $\mathrm{J}$ et al: ATAF1 transcription factor directly regulates abscisic acid biosynthetic gene NCED3 in Arabidopsis thaliana. Febs Open Bio 2013, 3:321-327.

28. Kim YS, Kim SG, Park JE, Park HY, Lim MH, Chua NH, Park CM: A membrane-bound NAC transcription factor regulates cell division in Arabidopsis. Plant Cell 2006, 18(11):3132-3144.

29. Aida M, Ishida T, Tasaka M: Shoot apical meristem and cotyledon formation during Arabidopsis embryogenesis: interaction among the CUP-SHAPED COTYLEDON and SHOOT MERISTEMLESS genes. Development (Cambridge, England) 1999, 126(8):1563-1570.

30. Trupkin SA, Astigueta FH, Baigorria AH, Garcia MN, Delfosse VC, Gonzalez SA, de la Torre MCP, Moschen S, Lia VV, Fernandez $P$ et al: Identification and expression analysis of NAC transcription factors potentially involved in leaf and petal senescence in Petunia hybrida. Plant Science 2019, 287.

31. Kim SY, Kim SG, Kim YS, Seo PJ, Bae M, Yoon HK, Park CM: Exploring membrane-associated NAC transcription factors in Arabidopsis: implications for membrane biology in genome regulation. Nucleic Acids Research 2007, 35(1):203-213.

32. Fujita M, Fujita Y, Maruyama K, Seki M, Hiratsu K, Ohme-Takagi M, Tran LSP, Yamaguchi-Shinozaki K, Shinozaki K: A dehydration-induced NAC protein, RD26, is involved in a novel ABA-dependent stresssignaling pathway. Plant Journal 2004, 39(6):863-876.

33. Peng $X$, Wang $Q$, Wang $Y$, Cheng $B$, Zhao $Y$, Zhu S: A maize NAC transcription factor, ZmNAC34, negatively regulates starch synthesis in rice. Plant Cell Reports 2019, 38(12):1473-1484. 
34. Kubo M, Udagawa M, Nishikubo N, Horiguchi G, Yamaguchi M, Ito J, Mimura T, Fukuda H, Demura T: Transcription switches for protoxylem and metaxylem vessel formation. Genes \& Development 2005, 19(16):1855-1860.

35. Zhao CS, Avci U, Grant EH, Haigler CH, Beers EP: XND1, a member of the NAC domain family in Arabidopsis thaliana, negatively regulates lignocellulose synthesis and programmed cell death in xylem. Plant Journal 2008, 53(3):425-436.

36. Zhang $H$, Ying YQ, Wang J, Zhao XH, Zeng W, Beahan C, He JB, Chen XY, Bacic A, Song LL et al: Transcriptome analysis provides insights into xylogenesis formation in Moso bamboo (Phyllostachys edulis) shoot. Scientific Reports 2018, 8.

37. Wang LL, Zhao HS, Chen DL, Li LC, Sun HY, Lou YF, Gao ZM: Characterization and primary functional analysis of a bamboo NAC gene targeted by miR164b. Plant Cell Reports 2016, 35(6):1371-1383.

38. Wang TT, Wang HY, Cai DW, Gao YB, Zhang HX, Wang YS, Lin CT, Ma LY, Gu LF: Comprehensive profiling of rhizome-associated alternative splicing and alternative polyadenylation in moso bamboo (Phyllostachys edulis). Plant Journal 2017, 91(4):684-699.

39. Zhang LN, Ma PF, Zhang YX, Zeng CX, Zhao L, Li DZ: Using nuclear loci and allelic variation to disentangle the phylogeny of Phyllostachys (Poaceae, Bambusoideae). Molecular Phylogenetics and Evolution 2019, 137:222-235.

40. Shan XM, Yang KB, Xu XR, Zhu CL, Gao ZM: Genome-Wide Investigation of the NAC Gene Family and Its Potential Association with the Secondary Cell Wall in Moso Bamboo. Biomolecules 2019, 9(10).

41. Ooka H, Satoh K, Doi K, Nagata T, Otomo Y, Murakami K, Matsubara K, Osato N, Kawai J, Carninci P et al: Comprehensive analysis of NAC family genes in Oryza sativa and Arabidopsis thaliana. DNA Research 2003, 10(6):239-247.

42. Nuruzzaman M, Manimekalai R, Sharoni AM, Satoh K, Kondoh H, Ooka H, Kikuchi S: Genome-wide analysis of NAC transcription factor family in rice. Gene 2010, 465(1-2):30-44.

43. Zhu GR, Chen GX, Zhu JT, Zhu Y, Lu XB, Li XH, Hu YK, Yan YM: Molecular Characterization and Expression Profiling of NAC Transcription Factors in Brachypodium distachyon L. Plos One 2015, 10(10).

44. Kadier Y, Zu YY, Dai QM, Song G, Lin SW, Sun QP, Pan JB, Lu M: Genome-wide identification, classification and expression analysis of NAC family of genes in sorghum Sorghum bicolor (L.) Moench. Plant Growth Regulation 2017, 83(2):301-312.

45. Kaliyugam, Shiriga, Rinku, Sharma, Krishan, Kumar, Shiv, Kumar, Yadav, Firoz: Genome-wide identification and expression pattern of drought-responsive members of the NAC family in maize.

46. Altschul SF, Madden TL, Schaffer AA, Zhang J, Zhang Z, Miller W, Lipman DJ: Gapped BLAST and PSI-BLAST: a new generation of protein database search programs. Nucleic acids research 1997, 25(17):3389-3402.

47. Chen $\mathrm{C}$, Chen $\mathrm{H}, \mathrm{He} \mathrm{Y}$, Xia R: TBtools, a toolkit for biologists integrating various biological data handling tools with a user-friendly interface. BioRxiv 2018:289660. 
48. Wang YJ, Liu HL, Zhu DY, Gao YM, Yan HW, Xiang Y: Genome-wide analysis of VQ motif-containing proteins in Moso bamboo (Phyllostachys edulis). Planta 2017, 246(1):165-181.

49. Tamura K, Stecher G, Peterson D, Filipski A, Kumar S: MEGA6: Molecular Evolutionary Genetics Analysis Version 6.0. Molecular Biology and Evolution 2013, 30(12):2725-2729.

50. Gao YM, Liu HL, Wang YJ, Li F, Xiang Y: Genome-wide identification of PHD-finger genes and expression pattern analysis under various treatments in moso bamboo (Phyllostachys edulis). Plant Physiology and Biochemistry 2018, 123:378-391.

51. Hu B, Jin JP, Guo AY, Zhang H, Luo JC, Gao G: GSDS 2.0: an upgraded gene feature visualization server. Bioinformatics 2015, 31(8):1296-1297.

52. Bailey TL, Boden M, Buske FA, Frith M, Grant CE, Clementi L, Ren J, Li WW, Noble WS: MEME SUITE: tools for motif discovery and searching. Nucleic Acids Research 2009, 37:W202-W208.

53. Wang YP, Li JP, Paterson AH: MCScanX-transposed: detecting transposed gene duplications based on multiple colinearity scans. Bioinformatics 2013, 29(11):1458-1460.

54. Liu HL, Ww M, Li F, Gao YM, Chen F, Xiang Y: TCP Transcription Factors in Moso Bamboo (Phyllostachys edulis): Genome-Wide Identification and Expression Analysis. Frontiers in Plant Science 2018, 9.

55. Cheng XR, Xiong R, Liu HL, Wu M, Chen F, Yan HW, Xiang Y: Basic helix-loop-helix gene family: Genome wide identification, phylogeny, and expression in Moso bamboo. Plant Physiology and Biochemistry 2018, 132:104-119.

56. Lescot M, Dehais P, Thijs G, Marchal K, Moreau Y, Van de Peer Y, Rouze P, Rombauts S: PlantCARE, a database of plant cis-acting regulatory elements and a portal to tools for in silico analysis of promoter sequences. Nucleic Acids Research 2002, 30(1):325-327.

57. Fan C, Ma J, Guo Q, Li X, Wang H, Lu M: Selection of reference genes for quantitative real-time PCR in bamboo (Phyllostachys edulis). PloS one 2013, 8(2).

58. Pan F, Wang Y, Liu H, Wu M, Chu W, Chen D, Xiang Y: Genome-wide identification and expression analysis of SBP-like transcription factor genes in Moso Bamboo (Phyllostachys edulis). BMC genomics 2017, 18(1):486.

59. Qiao X, Li Q, Yin H, Qi K, Li L, Wang R, Zhang S, Paterson AH: Gene duplication and evolution in recurring polyploidization-diploidization cycles in plants. Genome biology 2019, 20(1):38.

60. He X, Zhu LF, Xu L, Guo WF, Zhang XL: GhATAF1, a NAC transcription factor, confers abiotic and biotic stress responses by regulating phytohormonal signaling networks. Plant Cell Reports 2016, 35(10):2167-2179.

61. Hong YB, Zhang HJ, Huang L, Li DY, Song FM: Overexpression of a Stress-Responsive NAC Transcription Factor Gene ONACO22 Improves Drought and Salt Tolerance in Rice. Frontiers in Plant Science 2016, 7.

62. Sun L, Li D, Zhang H, Song F: Functions of NAC transcription factors in biotic and abiotic stress responses in plants. Yi chuan= Hereditas 2012, 34(8):993-1002. 
63. Xu ZY, Kim SY, Hyeon DY, Kim DH, Dong T, Park Y, Jin JB, Joo SH, Kim SK, Hong JC et al: The Arabidopsis NAC Transcription Factor ANAC096 Cooperates with bZIP-Type Transcription Factors in Dehydration and Osmotic Stress Responses. Plant Cel/2013, 25(11):4708-4724.

64. Li X, Chang Y, Ma SQ, Shen JQ, Hu HH, Xiong LZ: Genome-Wide Identification of SNAC1-Targeted Genes Involved in Drought Response in Rice. Frontiers in Plant Science 2019, 10.

65. Sun Q, Jiang S, Zhang T, Xu H, Fang H, Zhang J, Su M, Wang Y, Zhang Z, Wang N: Apple NAC transcription factor MdNAC52 regulates biosynthesis of anthocyanin and proanthocyanidin through MdMYB9 and MdMYB11. Plant Science 2019, 289:110286.

66. Wang Wq, Wang J, Wu Yy, Li Dw, Allan AC, Yin Xr: Genome-wide analysis of coding and non-coding RNA reveals a conserved miR164-NAC regulatory pathway for fruit ripening. New Phytologist 2020, 225(4):1618-1634.

67. Singh AK, Sharma V, Pal AK, Acharya V, Ahuja PS: Genome-Wide Organization and Expression Profiling of the NAC Transcription Factor Family in Potato (Solanum tuberosum L.). DNA Research 2013, 20(4):403-423.

68. Le DT, Nishiyama R, Watanabe Y, Mochida K, Yamaguchi-Shinozaki K, Shinozaki K, Tran L-SP: Genome-wide survey and expression analysis of the plant-specific NAC transcription factor family in soybean during development and dehydration stress. DNA research 2011, 18(4):263-276.

69. Hu R, Qi G, Kong Y, Kong D, Gao Q, Zhou G: Comprehensive analysis of NAC domain transcription factor gene family in Populus trichocarpa. BMC plant biology 2010, 10(1):145.

70. Ahmad M, Yan X, Li J, Yang Q, Jamil W, Teng Y, Bai S: Genome wide identification and predicted functional analyses of NAC transcription factors in Asian pears. Bmc Plant Biology 2018, 18.

71. Dennis C, Surridge C: A. thaliana genome. Nature 2000, 408(6814):791-791.

72. Consortium PGS: Genome sequence and analysis of the tuber crop potato. Nature 2011, 475(7355):189.

73. Tuskan GA, Difazio S, Jansson S, Bohlmann J, Grigoriev I, Hellsten U, Putnam N, Ralph S, Rombauts S, Salamov A: The genome of black cottonwood, Populus trichocarpa (Torr. \& Gray). science 2006, 313(5793):1596-1604.

74. Wu J, Wang Z, Shi Z, Zhang S, Ming R, Zhu S, Khan MA, Tao S, Korban SS, Wang H: The genome of the pear (Pyrus bretschneideri Rehd.). Genome research 2013, 23(2):396-408.

75. Shen YT, Liu J, Geng HY, Zhang JX, Liu YC, Zhang HK, Xing SL, Du JC, Ma SS, Tian ZX: De novo assembly of a Chinese soybean genome. Science China-Life Sciences 2018, 61(8):871-884.

76. Bowers JE, Chapman BA, Rong J, Paterson AH: Unravelling angiosperm genome evolution by phylogenetic analysis of chromosomal duplication events. Nature 2003, 422(6930):433-438.

77. Cheng TC, Fu BH, Wu YQ, Long RW, Liu C, Xia QY: Transcriptome Sequencing and Positive Selected Genes Analysis of Bombyx mandarina. Plos One 2015, 10(3).

78. Ohnishi T, Sugahara S, Yamada T, Kikuchi K, Yoshiba Y, Hirano HY, Tsutsumi N: OsNAC6, a member of the NAC gene family, is induced by various stresses in rice. Genes \& Genetic Systems 2005, 
80(2):135-139.

79. Nakashima K, Tran L-SP, Van Nguyen D, Fujita M, Maruyama K, Todaka D, Ito Y, Hayashi N, Shinozaki $\mathrm{K}$, Yamaguchi-Shinozaki K: Functional analysis of a NAC-type transcription factor OsNAC6 involved in abiotic and biotic stress-responsive gene expression in rice. Plant and Cell Physiology 2007, 48:S106-S106.

80. Lee DK, Chung PJ, Jeong JS, Jang G, Bang SW, Jung H, Kim YS, Ha SH, Choi YD, Kim JK: The rice OsNAC6 transcription factor orchestrates multiple molecular mechanisms involving root structural adaptions and nicotianamine biosynthesis for drought tolerance. Plant Biotechnology Journal 2017, 15(6):754-764.

81. Munné-Bosch S, Müller M: Hormonal cross-talk in plant development and stress responses. Frontiers in plant science $2013,4: 529$.

82. Riemann M, Dhakarey R, Hazman M, Miro B, Kohli A, Nick P: Exploring jasmonates in the hormonal network of drought and salinity responses. Frontiers in plant science 2015, 6:1077.

83. de Ollas C, Dodd IC: Physiological impacts of ABA-JA interactions under water-limitation. Plant molecular biology 2016, 91(6):641-650.

84. Su L, Fang L, Zhu Z, Zhang L, Sun X, Wang Y, Wang Q, Li S, Xin H: The transcription factor VaNAC17 from grapevine (Vitis amurensis) enhances drought tolerance by modulating jasmonic acid biosynthesis in transgenic Arabidopsis. Plant Cell Reports 2020:1-14.

\section{Figures}




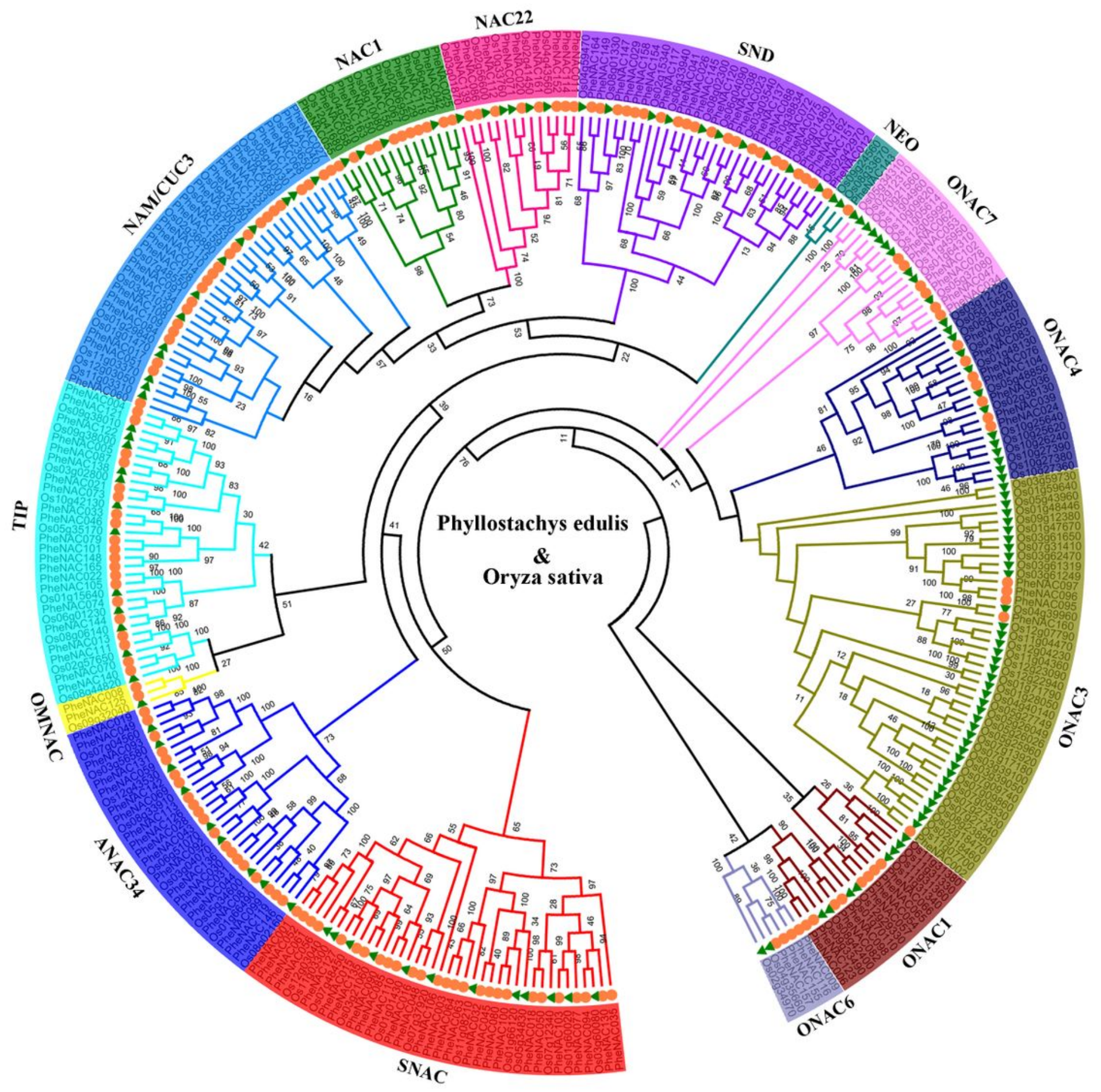

Figure 1

Phylogenetic tree of the domains from 165 PheNACs and 143 OsNACs. The phylogenetic tree of the NAM domain sequence was constructed using the neighbor-joining method with 100 bootstrap replicates. And the PheNAC members were divided into 14 distinct groups, which were marked with different colors, respectively. 


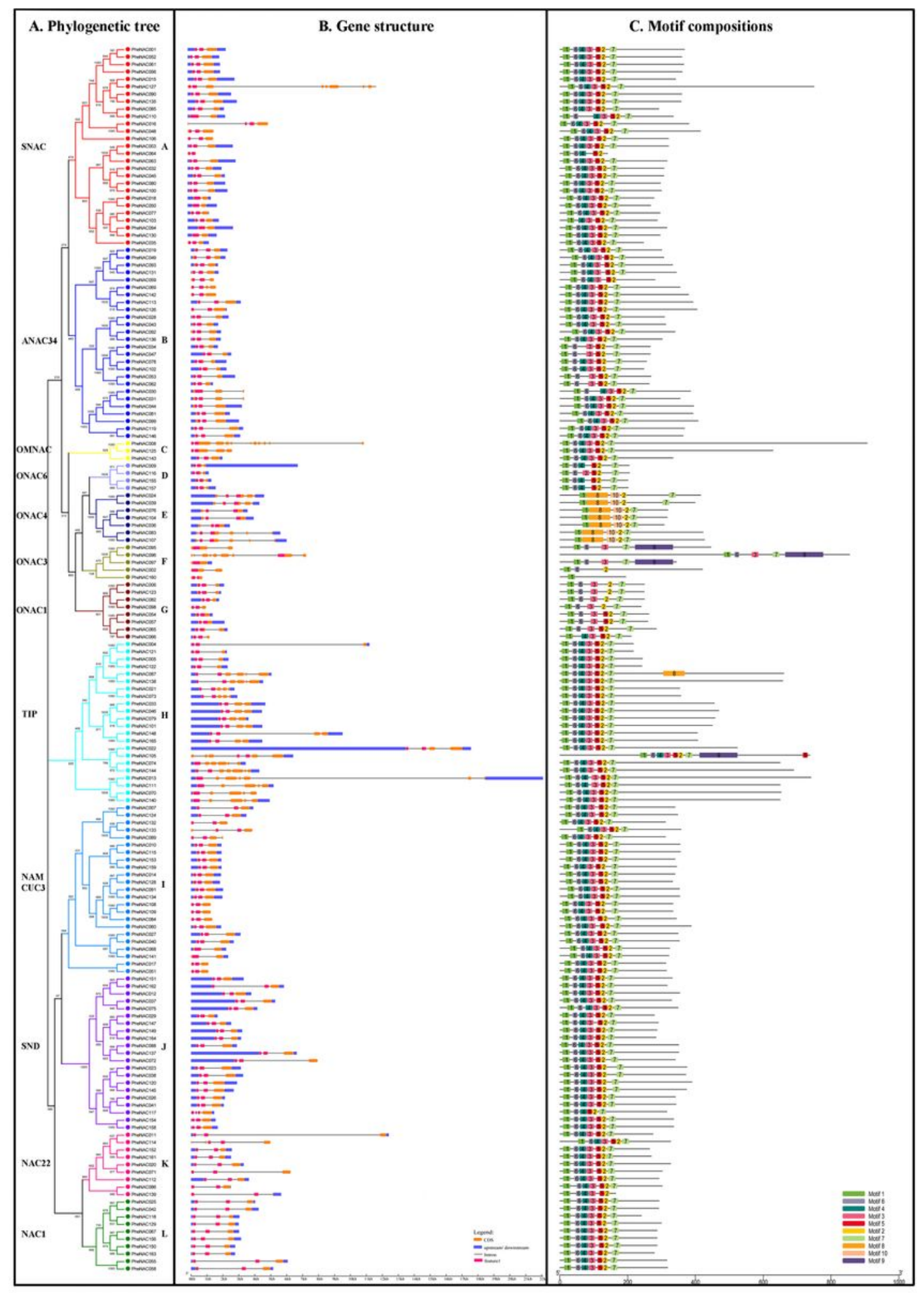

Figure 2

Phylogenetic tree, gene structure and conserved motifs of 165 PheNACs. A: The Phylogenetic tree of 165 PheNACs was built by $\mathrm{N}-\mathrm{J}$ method in MEGA6.0 with 1000 bootstrap values. B: CDS, intron, upstream/downstream and NAM domain (feature 1) were presented by different colors. C: All motifs were identified by MEME using the complete amino acid sequences of 165 NAC proteins. Each motif was 
indicated with a different-colored box and numbered 1-10; motif details were listed in Additional file 9: Table S7.
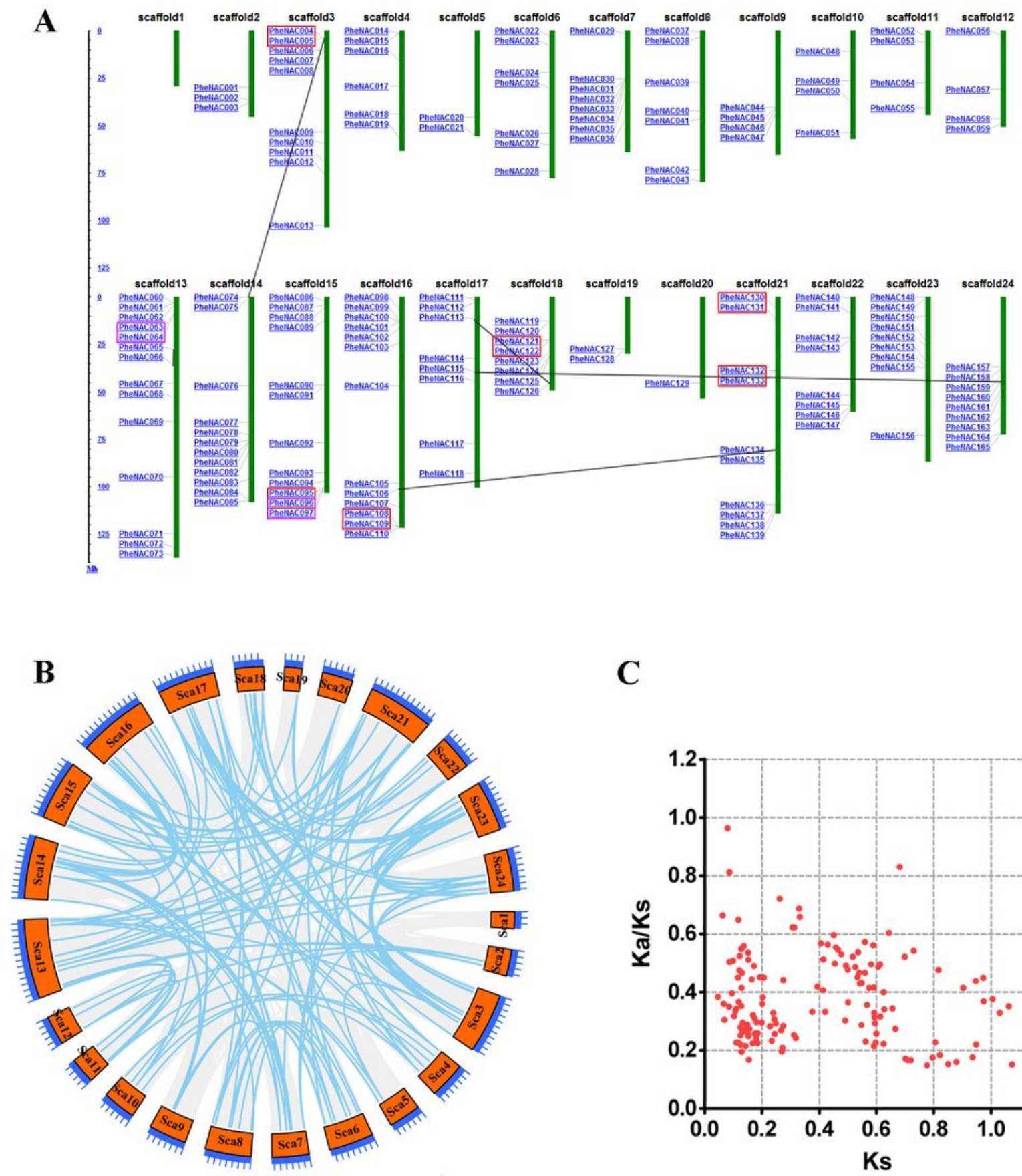

C

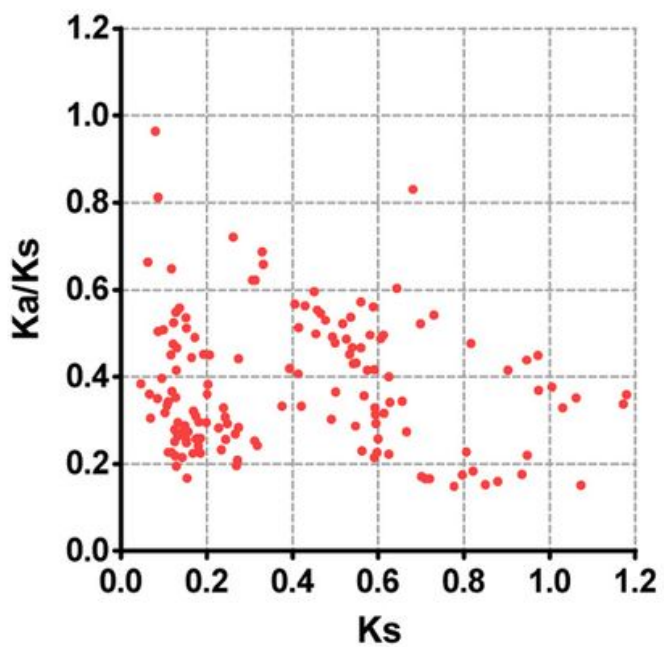

Figure 3

Scaffold location and gene duplication of PheNAC genes. A The 165 PheNAC genes were unevenly distributed on 23 scaffolds and scaffold numbers were indicated at the top of each vertical bar. The paralogous pairs of tandem duplication were marked with red rectangle frame, proximal duplication pairs were colored with purple rectangle frame and transposed duplication pairs were connected with gray 
lines. B Orange blocks were moso bamboo scaffolds and the segmental duplicated pairs were connected with blue lines. $\mathrm{C}$ The distribution of $\mathrm{Ks}$ and $\mathrm{Ka} / \mathrm{Ks}$ of 150 paralogous pairs (5 pair had no ks value).

A

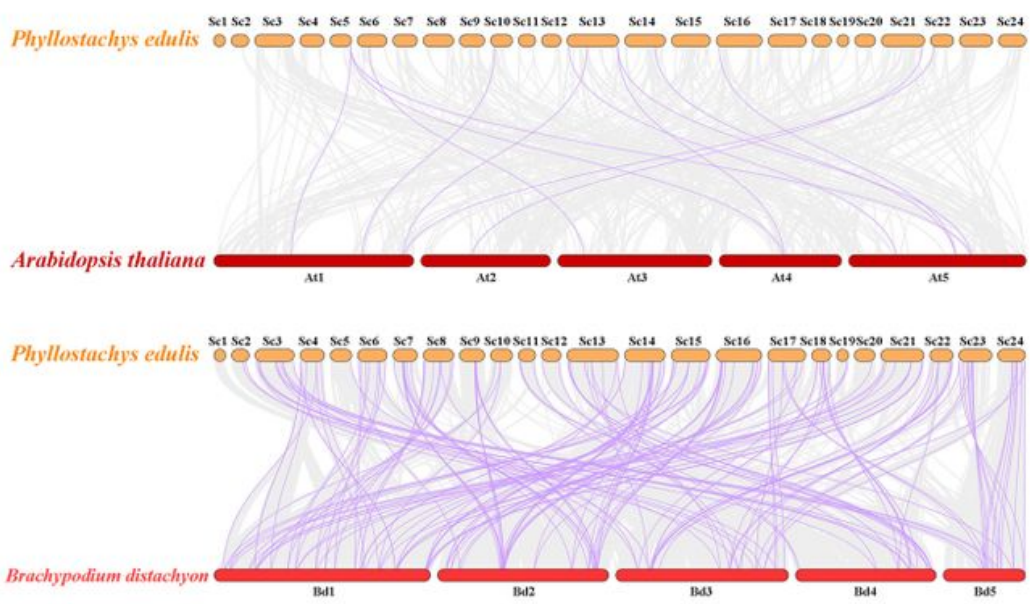

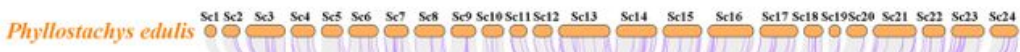

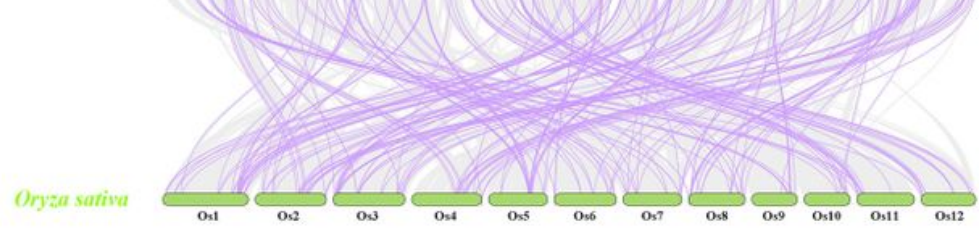

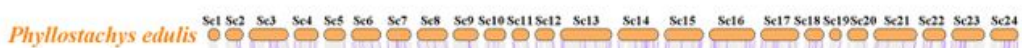

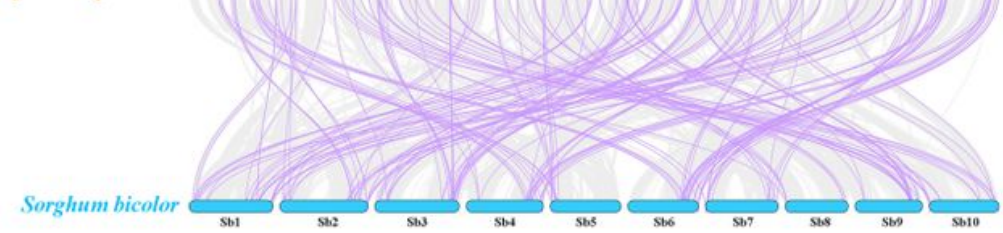

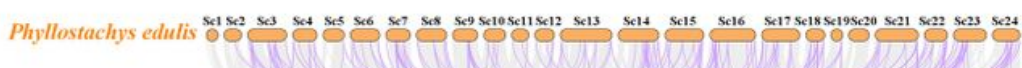

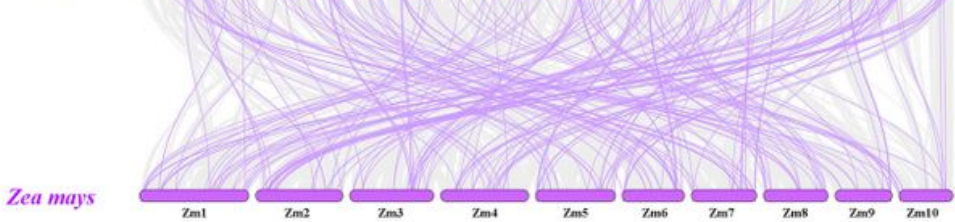

\section{B}

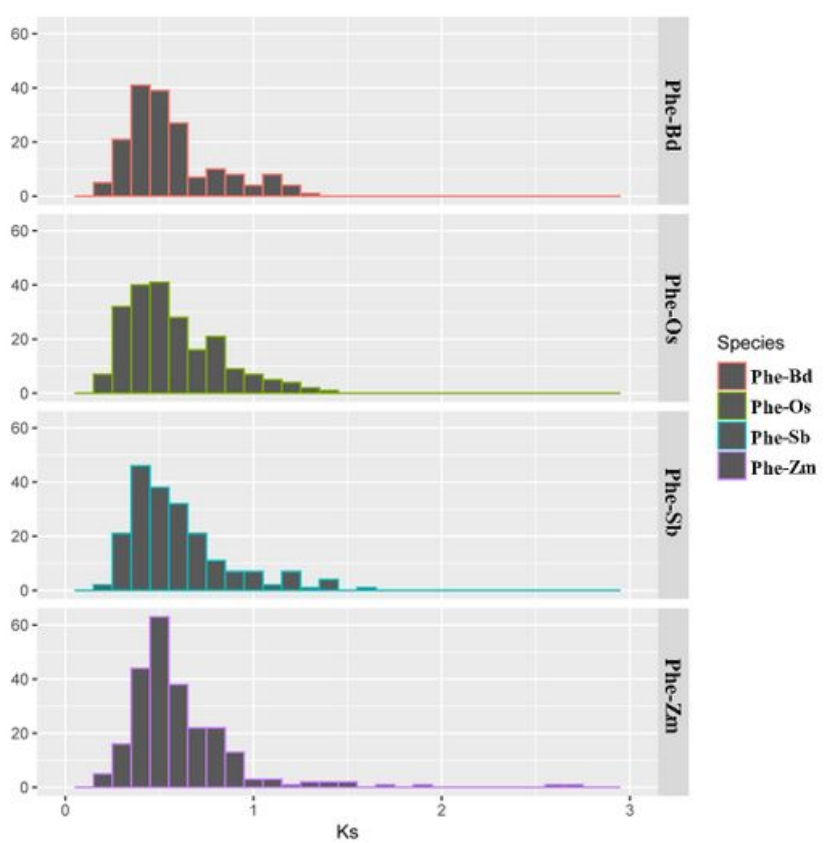

C
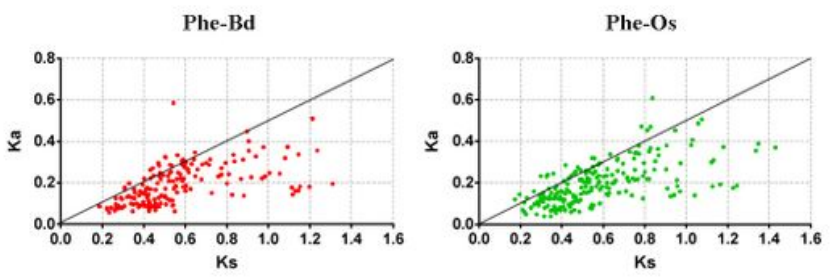

Phe-Sb

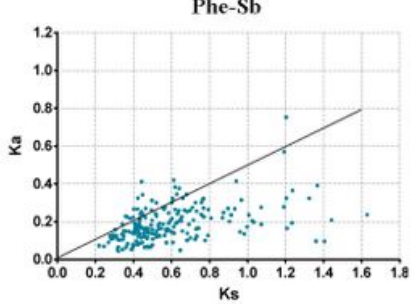

\section{Figure 4}

A Microsynteny analysis of NAC genes between moso bamboo and other plant species. Gray lines in the background indicated the collinear blocks within the moso bamboo genome and other species, whereas the purple lines highlighted the collinear of NAC gene pairs. B The Ks frequency distribution of moso bamboo with other four grass plants. $\mathrm{C}$ the distributions of Ka, Ks values of orthohomologous pairs between moso bamboo and other four species and the black lines represented slopes of $\mathrm{Ka} / \mathrm{Ks}=0.5$. Four species were Brachypodium distachyon, Oryza sativa, Sorghum bicolor and Zea mays, respectively. 


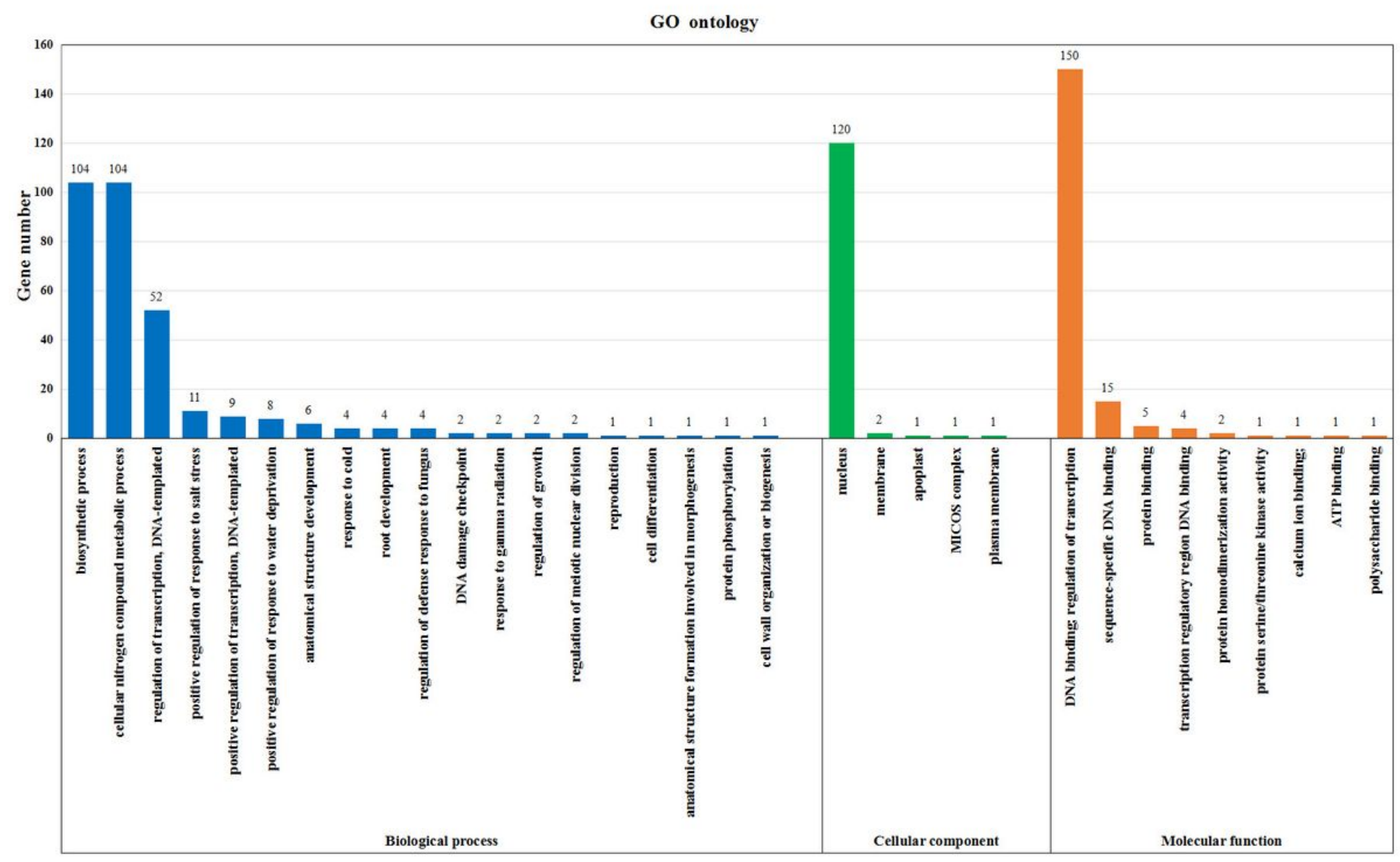

Figure 5

The statistics and classification of gene ontology annotation for 165 PheNACs: biological process, cellular component and molecular function. 
A

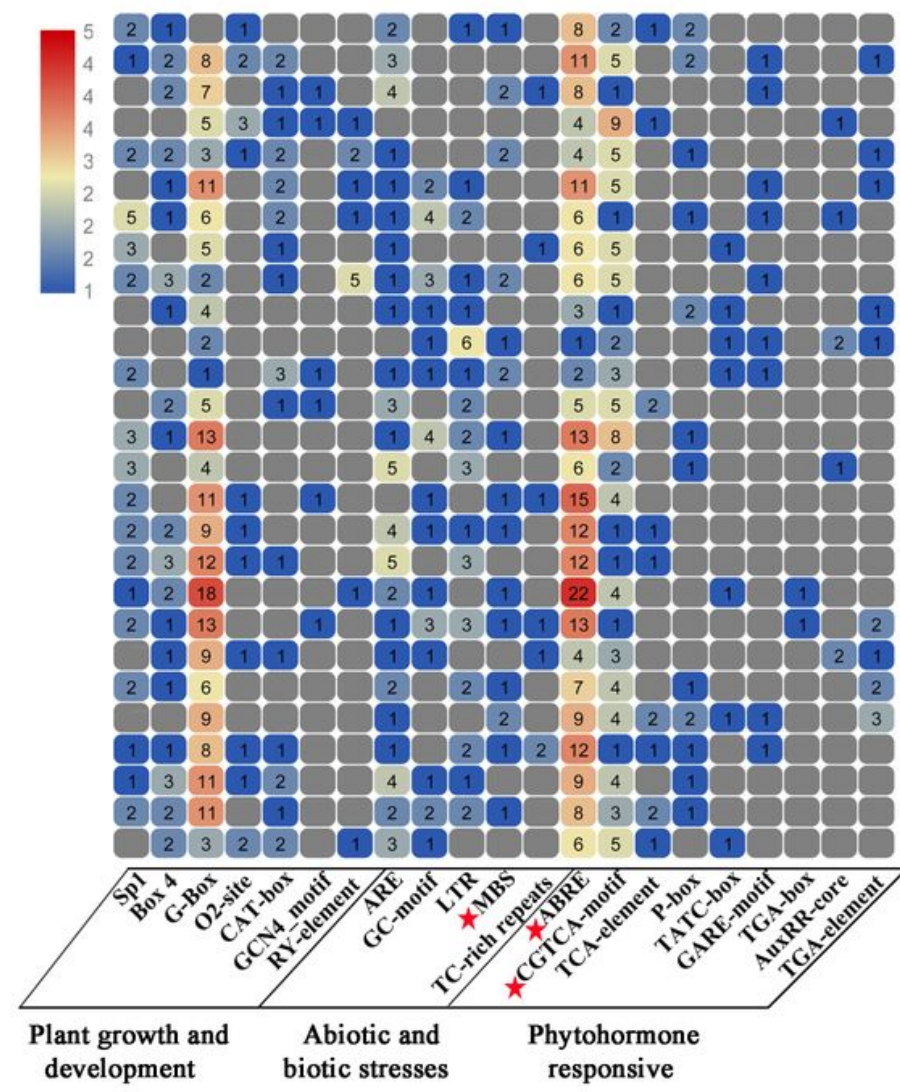

B

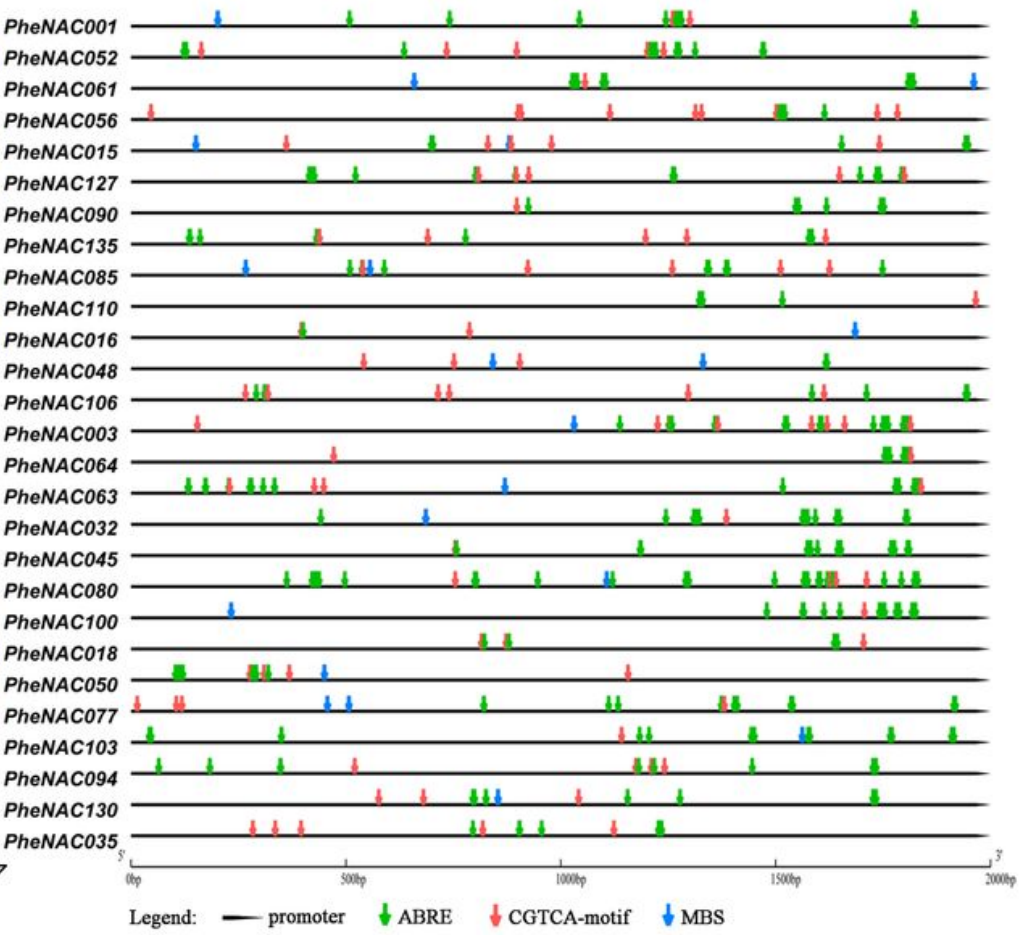

\section{Figure 6}

The investigation of promoter element numbers for the 27 NAC genes in A subfamily. A The numbers of different promoter elements for the 27 NAC genes were counted. B The specific locations of the three kinds of cis-acting elements (ABRE, CGTCA-motif and MBS) were depicted in the promoter region of 27 NAC genes. 


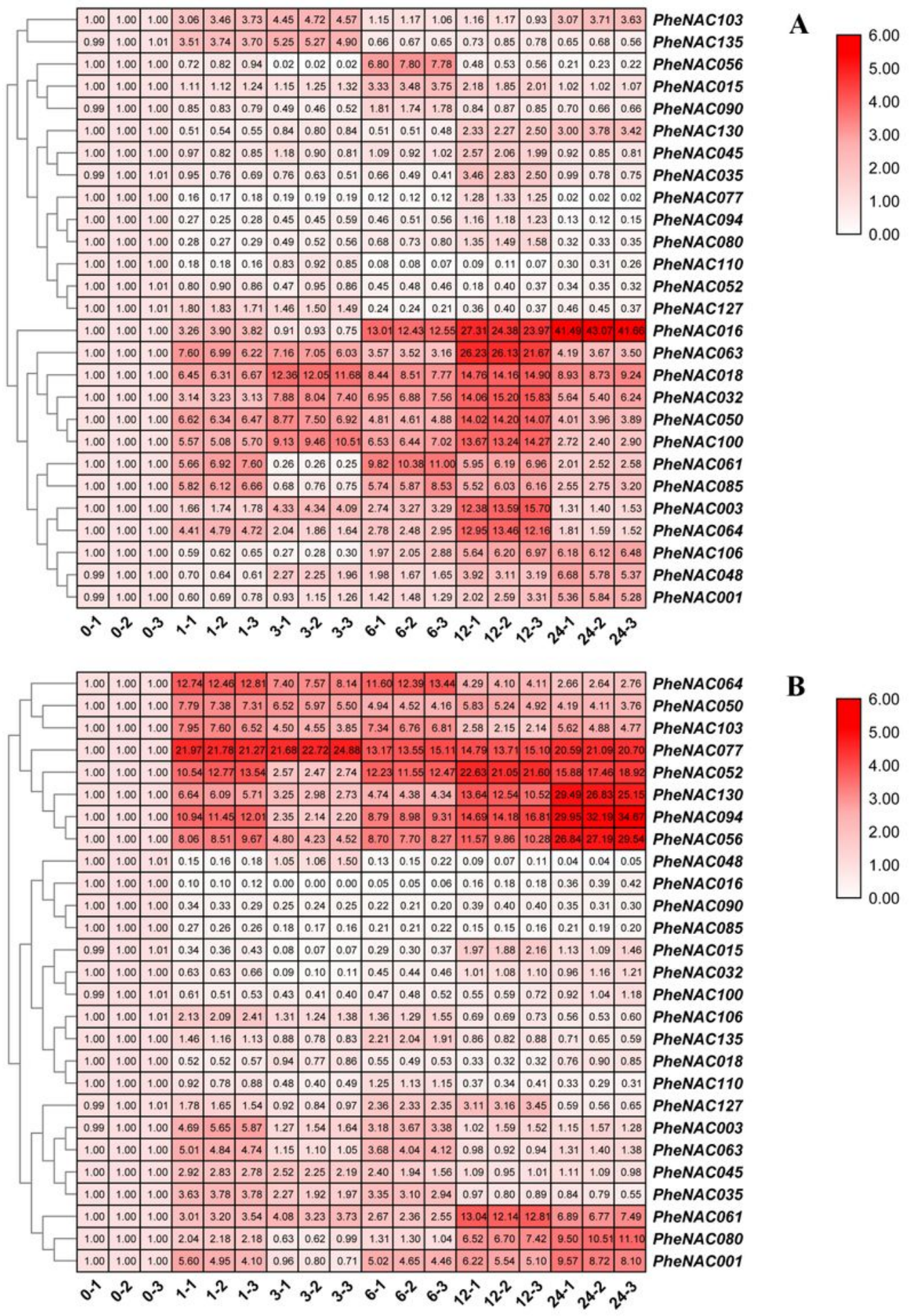

\section{Figure 7}

Expression analysis of PheNAC genes under $20 \%$ PEG6000 and $200 \mathrm{mM} \mathrm{NaCl}$ treatments. A The expression levels of 27 NAC members after 20\% PEG6000 treatment were showed in heatmap at different time points and each sample had three replicates. The deeper the color, the higher the expression. B The expression levels of $27 \mathrm{NAC}$ members after $200 \mathrm{mM} \mathrm{NaCl}$ treatment were showed in heatmap at different time points and each sample had three replicates. The deeper the color, the higher the expression. 


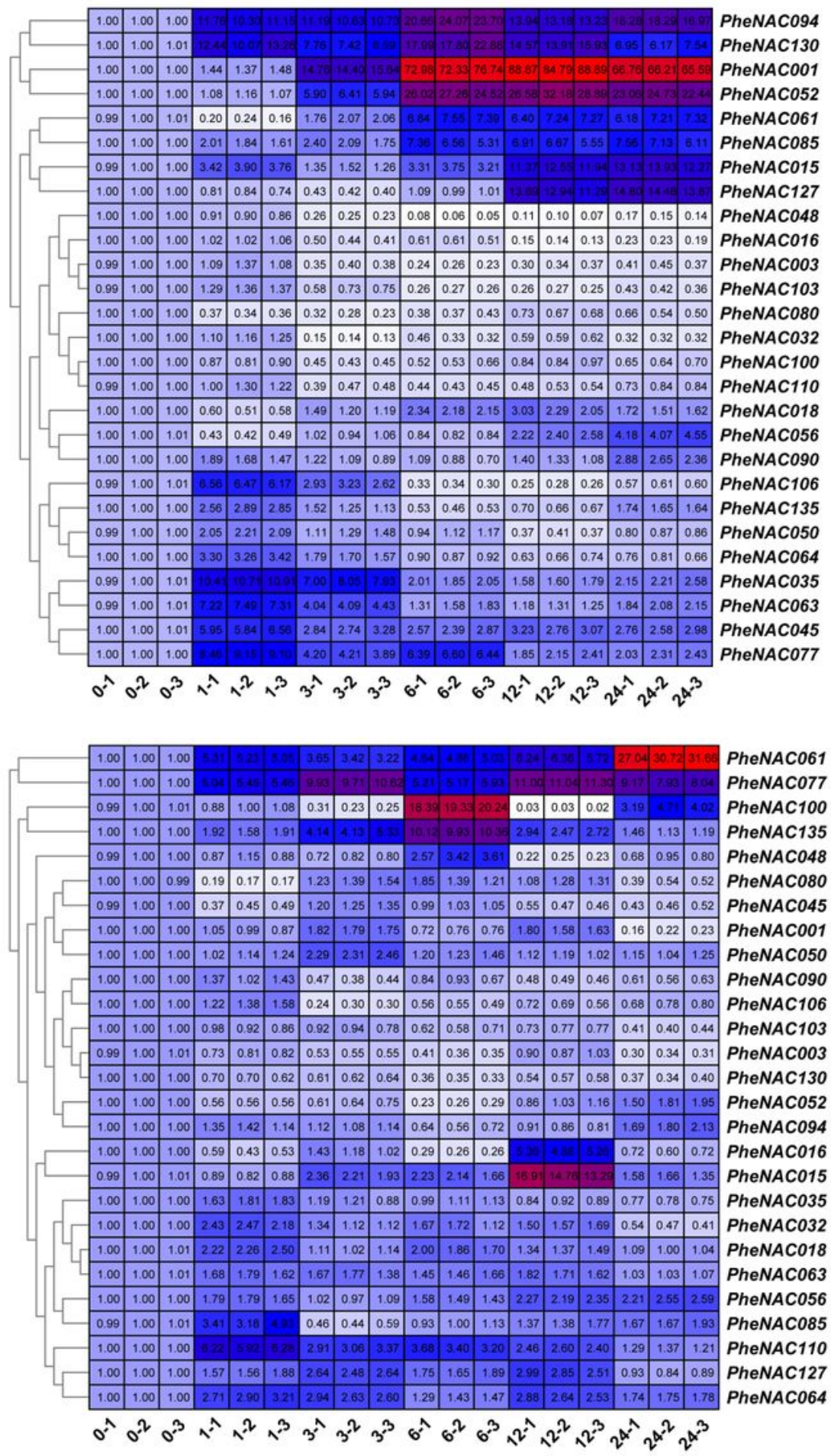

A

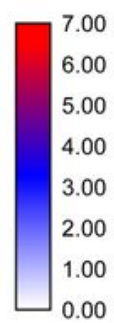

B

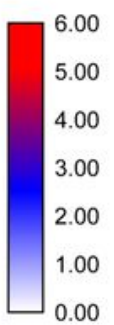

\section{Figure 8}

Expression analysis of PheNAC genes under $100 \mu \mathrm{M}$ ABA and $100 \mu \mathrm{M}$ MeJA treatments. A The expression levels of 27 NAC members after $100 \mu \mathrm{M}$ treatment were showed in heatmap at different time points and each sample had three replicates. The deeper the color, the higher the expression. B The expression levels of 27 NAC members after $100 \mu \mathrm{M}$ MeJA treatment were showed in heatmap at different time points and each sample had three replicates. The deeper the color, the higher the expression. 


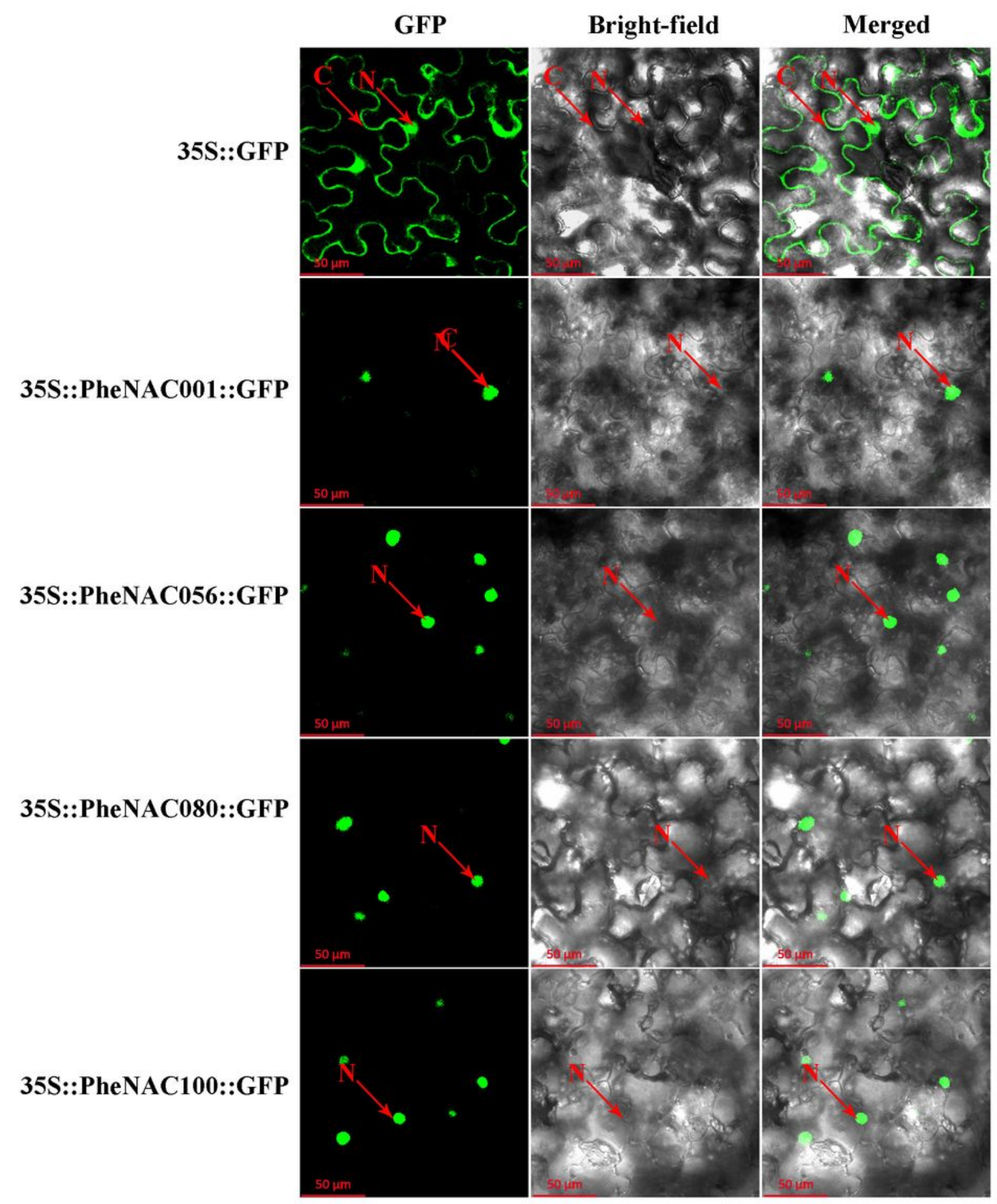

\section{Figure 9}

Subcellular localization of four PheNACs. The fusion proteins (35S::PheNAC001-GFP, 35S::PheNAC056::GFP, 35S::PheNAC080::GFP and 35S::PheNAC100::GFP) and the control (35S::GFP) were transiently expressed in Nicotiana tabacum leaves and observed under a fluorescence microscope. The red arrows indicated important areas ( $\mathrm{N}$ stands for the nucleus and $\mathrm{C}$ stands for the cell membrane). 


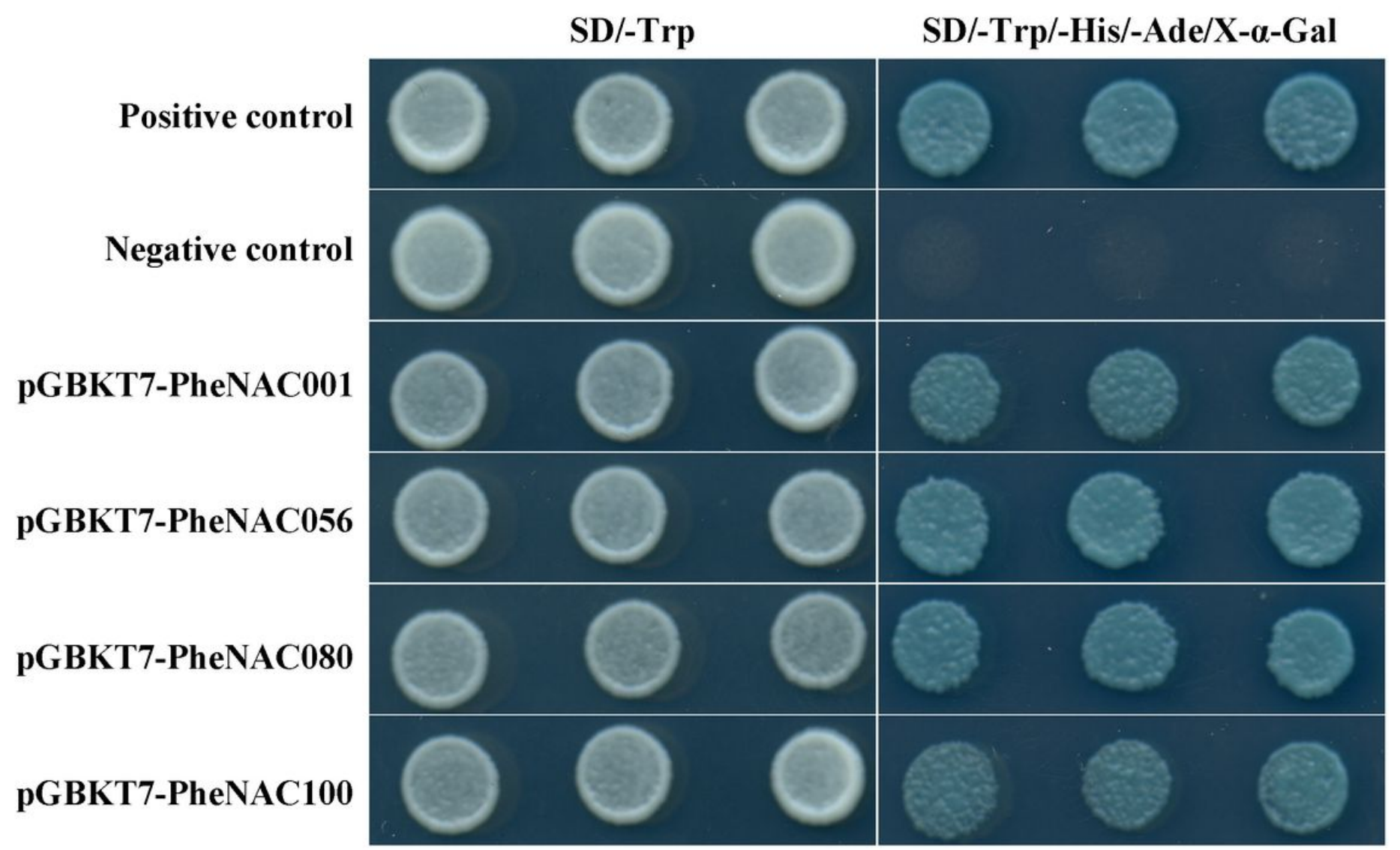

\section{Figure 10}

Transactivational analyses of four PheNAC proteins (PheNAC001, -056, -080 and -100) in yeast Y2HGold strain. The positive constructs, negative constructs, and fusion constructs were transformed into yeast strain and cultivated in SD/-Trp media and SD/-Trp/-His/-Ade/X-a-GAL media.

\section{Supplementary Files}

This is a list of supplementary files associated with this preprint. Click to download.

- Tables2.doc

- Figs2.tif

- FigS1.tif

- Tables1.doc

- Tables4.xls

- Tables5.xls

- TableS3.doc

- TableS6.doc 
- TableS7.doc

Page 32/32 